\title{
Microstructure and Damage Evolution During Thermal Cycling of Sn-Ag-Cu Solders Containing Antimony
}

\author{
S.A. BELYAKOV $\left(1,{ }^{1,5}\right.$ R.J. COYLE ${ }^{2}$ B. ARFAEI, ${ }^{3,4}$ J.W. XIAN, ${ }^{1}$ \\ and C.M. GOURLAY ${ }^{1}$ \\ 1.-Department of Materials, Imperial College, London SW7 2AZ, UK. 2.-Nokia Bell Labs, \\ Murray Hill, NJ, USA. 3.-Binghamton University, Binghamton, NY, USA. 4.-Ford Motor \\ Company, Palo Alto, CA, USA. 5.—e-mail: s.belyakov@imperial.ac.uk
}

\begin{abstract}
Antimony is attracting interest as an addition to $\mathrm{Pb}$-free solders to improve thermal cycling performance in harsher conditions. Here, we investigate microstructure evolution and failure in harsh accelerated thermal cycling (ATC) of a $\mathrm{Sn}-3.8 \mathrm{Ag}-0.9 \mathrm{Cu}$ solder with $5.5 \mathrm{wt} . \%$ antimony as the major addition in two ball grid array (BGA) packages. SbSn particles are shown to precipitate on both $\mathrm{Cu}_{6} \mathrm{Sn}_{5}$ and as cuboids in $\beta$-Sn, with reproducible orientation relationships and a good lattice match. Similar to $\mathrm{Sn}-\mathrm{Ag}-\mathrm{Cu}$ solders, the microstructure and damage evolution were generally localised in the $\beta$-Sn near the component side where localised $\beta$-Sn misorientations and subgrains, accelerated $\mathrm{SbSn}$ and $\mathrm{Ag}_{3} \mathrm{Sn}$ particle coarsening, and $\beta$-Sn recrystallisation occurred. Cracks grew along the network of recrystallised grain boundaries to failure. The improved ATC performance is mostly attributed to SbSn solidstate precipitation within $\beta$-Sn dendrites, which supplements the $\mathrm{Ag}_{3} \mathrm{Sn}$ that formed in a eutectic reaction between $\beta$-Sn dendrites, providing populations of strengthening particles in both the dendritic and eutectic $\beta$-Sn.
\end{abstract}

Key words: $\mathrm{Pb}$-free solder, accelerated thermal cycling, electron backscatter diffraction, thermal fatigue

\section{INTRODUCTION}

Accelerated thermal cycling (ATC) test programs have shown that $\mathrm{Sn}-\mathrm{Ag}-\mathrm{Cu}$ solders can outperform the $\mathrm{Sn}-37 \mathrm{~Pb}$ solder they were designed to replace. ${ }^{1}$ However, various applications now require solder joints to operate under harsher conditions, cycling through wider temperature ranges, with higher maximum temperatures and/or longer dwell times. It has been found that the beneficial effects of $\mathrm{Ag}$ on ATC reliability diminishes as the severity of the thermal cycle increases, ${ }^{1}$ making $\mathrm{Sn}-\mathrm{Ag}$-Cu solders unsuitable for some emerging applications in, for example, the automotive, aerospace and military sectors. To address this, a third generation of $\mathrm{Pb}-$

(Received July 14, 2020; accepted September 21, 2020; published online October 26, 2020) free solders is under development where the alloy design approach has been to provide additional strengthening mechanisms, including solid solution strengthening and improved precipitation strengthening. ${ }^{2-4}$ Many of the third-generation $\mathrm{Pb}$-free solders are complex multicomponent alloys based on near-eutectic $\mathrm{Sn}-\mathrm{Ag}-\mathrm{Cu}$ compositions with significant additions of $\mathrm{Bi}, \mathrm{Sb}$ and/or $\mathrm{In}$, often with a combined $\mathrm{Bi}+\mathrm{Sb}+\mathrm{In}$ content of $3.5-6.5 \mathrm{wt} . \% .^{2} \mathrm{In}$ this paper, we focus on the influence of a $5.5 \mathrm{wt} . \% \mathrm{Sb}$ addition to a near-eutectic $\mathrm{Sn}-\mathrm{Ag}-\mathrm{Cu}$ solder to build the understanding of its effect on microstructure evolution, precipitation strengthening, and failure mechanisms in thermal cycling.

$\mathrm{Sn}-\mathrm{Sb}$ solders containing $\sim 5 \% \mathrm{Sb}$ existed long before the transition to $\mathrm{Pb}$-free solders ${ }^{5,6}$ due to their higher strength and melting point compared with eutectic $\mathrm{Sn}-\mathrm{Pb}$ solder, and $\mathrm{Sn}-\mathrm{Sb}$ solders containing $\sim 5-10$ wt.\% Sb have been widely 
studied. ${ }^{7-15}$ However, there is limited understanding of the behaviour of $\mathrm{Sn}-\mathrm{Ag}$-Cu-based solders containing similar Sb additions and of the behaviour of SAC + Sb solders in ball grid array (BGA) packages undergoing thermal cycling.

Recently, an industrial consortium project tested the thermal fatigue performance of two packages soldered with a variety of emerging third-generation $\mathrm{Pb}$-free solders. ${ }^{16}$ These tests involved daisychained components soldered to custom test boards that were subjected to accelerated thermal cycling (ATC) profiles of different levels of harshness. Such testing programs allow the relative reliability of different solder alloys to be assessed and, by accelerating the fatigue damage mechanisms, enable characterisation studies of the microstructure and damage evolution that is likely to occur in service. We selected one composition, Sn-3.8Ag-0.9Cu5.5Sb-0.5In (wt.\%), for a detailed microstructural analysis in this paper. As summarised in Table I, Sn-3.8Ag-0.9Cu-5.5Sb-0.5In outperformed SAC305 (in terms of characteristic life) in both the 192CABGA and 84CTBGA packages in all thermal cycling profiles tested: $0 / 100^{\circ} \mathrm{C},-40 / 125^{\circ} \mathrm{C}$ and $-55 /$ $125^{\circ} \mathrm{C}$. It is important to note that various of the other third-generation solders also outperformed SAC305 in these tests, ${ }^{16}$ and we selected Sn-3.8Ag$0.9 \mathrm{Cu}-5.5 \mathrm{Sb}-0.5 \mathrm{In}$ for this study because it has $\mathrm{Sb}$ as the only major addition, making it suited to a study of the effects of Sb additions on microstructure and damage evolution in SAC + Sb solders. The $0.5 \mathrm{wt}$ \% In addition in this solder composition did not cause any noticeable microstructural effect, ${ }^{17}$ although further work is required to test whether this small indium addition affects the intermetallic compounds (IMCs) and reliability significantly.

Since these solders are targeting application in harsh conditions, for this microstructure characterisation study, we chose packages that had been through the harshest cycle used $\left(-55 / 125^{\circ} \mathrm{C}\right.$ with 10-min dwell times). The thermally cycled test boards studied here were taken directly from the studies reported in ${ }^{16,18}$ and summarised in Table I.

\section{METHODS}

\section{Test Vehicle, Soldering and Thermal Cycling}

The thermal cycling test vehicle consists of two daisy-chained BGAs, a 192CABGA and a 84CTBGA, and a matching daisy-chained printed circuit board (PCB). A single daisy-chained loop per component is designed for in situ resistance monitoring during thermal cycling. Component pin diagrams and a fully populated test board are shown in Ref.2 The physical attributes of the components and PCB are provided in Table II. Of these two packages, the 192CABGA experiences the highest thermal strain per cycle ${ }^{1}$ which is the main origin of the lower number of cycles to failure for the 192CABGA compared with the 84CTBGA in Table I. Figure 1
Table I. Summary of the characteristic life (N63.2) from two-parameter Weibull analysis of thermal cycling of Sn-3.8Ag-0.9Cu-5.5Sb-0.5In (labelled SAC + Sb) and a SAC305 baseline alloy in two packages and three thermal cycling profiles, all with $10-\mathrm{K} \mathrm{min}^{-1}$ ramp rates and 10-min dwells ${ }^{16,18}$

\begin{tabular}{|c|c|c|c|c|}
\hline & \multicolumn{2}{|c|}{ 192CABGA } & \multicolumn{2}{|c|}{ 84CTBGA } \\
\hline & SAC305 & $\mathbf{S A C}+\mathbf{S b}$ & SAC305 & $\mathbf{S A C}+\mathbf{S b}$ \\
\hline $0 / 100^{\circ} \mathrm{C}$ & 5442 & 6917 & 7286 & 14997 \\
\hline$-40 / 125^{\circ} \mathrm{C}$ & 1692 & 2698 & 2758 & 5035 \\
\hline$-55 / 125^{\circ} \mathrm{C}$ & 1123 & 1765 & 1946 & 3151 \\
\hline
\end{tabular}

gives examples of both components and their crosssections after thermal cycling.

The components were purchased as land-grid arrays (LGA), and a flux-only process was used to attach the $3.8 \mathrm{Ag}-0.9 \mathrm{Cu}-5.5 \mathrm{Sb}-0.5 \mathrm{In}$ alloy spheres. Balls of $460 \mu \mathrm{m}$ were used for the 192CABGA, and $300 \mu \mathrm{m}$ balls for the 84CTBGA. The solder assembly of the test vehicles was performed using a 5-mil (125 $\mu \mathrm{m})$-thick stencil with 14-mil (0.35 mm)-diameter round apertures for the larger 192CABGA and $12 \mathrm{mil} \times 12 \mathrm{mil}(0.3 \mathrm{~mm} \times 0.3 \mathrm{~mm})$ square apertures for the smaller 84CTBGA. A type 4 no-clean solder paste with a matching $3.8 \mathrm{Ag}-0.9 \mathrm{Cu}-5.5 \mathrm{Sb}-$ 0.5 In composition was used for the final assemblies. The nominal peak reflow temperature measured on the board adjacent to the solder joints was $245^{\circ} \mathrm{C}$. The reflow operation was performed in a 14-temperature zone convection oven in a nitrogen atmosphere.

The daisy-chained components and the test circuit boards enabled electrical continuity testing after surface mount assembly and in situ, continuous monitoring during thermal cycling. Thermal cycling was done in accordance with the IPC-9701A guideline ${ }^{19}$ using three thermal profiles: $0 / 100^{\circ} \mathrm{C}$, $-40 / 125^{\circ} \mathrm{C}$ and $-55 / 125^{\circ} \mathrm{C}$. The solder joints were monitored using an event detector set at a resistance limit of $1000 \mathrm{ohms}$. The failure data in Table I are reported as characteristic lifetime (the number of cycles to achieve $63.2 \%$ failure) and slope from a two-parameter (2-P) Weibull analysis. Only the $-55 / 125^{\circ} \mathrm{C}$ samples were studied here.

\section{Microstructure Characterisation}

The 192CABGA and 84CTBGA components were cut from the test vehicle and mounted in Struers VersoCit II acrylic cold mounting resin and wet ground to 4000 grit $\mathrm{SiC}$ paper followed by polishing with colloidal silica. Analytical scanning electron microscopy (SEM) was conducted on a Zeiss SIGMA field-emission gun scanning electron microscope (Carl Zeiss, Oberkochen, Germany) equipped with an Oxford Instruments Inca X-sight energy- 


\begin{tabular}{|c|c|}
\hline \multicolumn{2}{|c|}{ BGA package attributes } \\
\hline Designation & 84CTBGA \\
\hline Die size & $5 \times 5 \mathrm{~mm}$ \\
\hline Package size & $7 \times 7 \mathrm{~mm}$ \\
\hline Ball array & $12 \times 12$ \\
\hline Ball pitch & $0.5 \mathrm{~mm}$ \\
\hline Ball diameter & $0.3 \mathrm{~mm}$ \\
\hline Pad diameter & $0.3 \mathrm{~mm}$ \\
\hline Pad finish & Electrolytic Ni/Au \\
\hline $\mathrm{Au}$ thickness & $0.6 \mu \mathrm{m}$ \\
\hline \multicolumn{2}{|l|}{ PCB attributes } \\
\hline Dimensions & $165 \times 178 \times 2.36 \mathrm{~mm}$ \\
\hline Laminate & Panasonic R-1755 V \\
\hline Surface finish & Entek HT OSP \\
\hline No. Cu layers & 6 \\
\hline Pad diameter & $0.254 \mathrm{~mm}$ \\
\hline Solder mask dia. & $0.381 \mathrm{~mm}$ \\
\hline $\begin{array}{l}\text { Glass transition } \\
\text { temperature, Tn }\end{array}$ & $165^{\circ} \mathrm{C}$ \\
\hline $\begin{array}{l}\text { Decomposition } \\
\quad \text { temperature, } \mathrm{Td}\end{array}$ & $350^{\circ} \mathrm{C}$ \\
\hline $\begin{array}{l}\text { Room-temperature } \\
\text { storage modulus }\end{array}$ & $11.6 \mathrm{GPa}$ \\
\hline
\end{tabular}

dispersive X-ray (EDX) detector (Oxford Instruments, Oxfordshire, UK) and a Bruker electron backscatter diffraction (EBSD) detector (Bruker AXS Inc., Fitchburg, WI, USA). The prepared cross-sections were carbon-coated before EBSD analysis. Quantification of the size and distribution of SbSn and $\mathrm{Ag}_{3} \mathrm{Sn}$ particles in SEM images was performed using ImageJ processing software. ${ }^{20}$

EBSD maps were analysed within Bruker Esprit 2.1. Five phases were detected in the bulk solder of these joints by combining EDS with EBSD: $\beta$-Sn, $\mathrm{Cu}_{6} \mathrm{Sn}_{5}, \mathrm{Ag}_{3} \mathrm{Sn}, \mathrm{SbSn}$ and InSb, although InSb was only present as traces. Crystallographic details of the phases used for EBSD indexing are shown in Table III with references to the original studies. Note that Table III only contains the phases used for EBSD indexing. Further work is required to explore how $\mathrm{Sb}$ and In affect the crystallography of $\mathrm{Cu}_{6}(\mathrm{Sn}, \mathrm{Sb}, \mathrm{In})_{5}$ and $\mathrm{Ag}_{3}(\mathrm{Sn}, \mathrm{Sb}, \mathrm{In})$. In Table III, three structures are listed for SbSn. The NaCl-type cubic structure was originally assigned to $\mathrm{SbSn}^{21}$ before modern diffractometers were used. It was later shown that $\mathrm{SbSn}$ is a small rhombohedral distortion $\left(\alpha \sim 89.8^{\circ}\right)$ from the $\mathrm{NaCl}$ structure ${ }^{22}$ with incommensurate modulation. ${ }^{23-25}$ Recently ${ }^{24-26}$ it has been shown that there is another compound at the Sn-rich end of the SbSn composition field with stoichiometry $\mathrm{Sb}_{3} \mathrm{Sn}_{4}$. This phase has a crystal structure closely related to $\mathrm{SbSn}$ and is a commensurately modulated $1 \times 1 \times 7$ superstructure (in terms of the hexagonal cell setting) of the rhombohedral SbSn phase at the
high-Sn limit. ${ }^{25}$ Inspecting Table III, it can be seen that, when using the rhombohedral cell setting, a $2 \times 2 \times 2$ supercell of $\mathrm{SbSn}$ and $\mathrm{Sb}_{3} \mathrm{Sn}_{4}$ both have lattice parameters $6.13 \AA$ and $\alpha \approx 89.8^{\circ}$, showing the link to the cubic NaCl structure of $\mathrm{SbSn}$ proposed in early studies. Based on the study of Schmetterer et al., ${ }^{25}$ for a 5.5 wt.\% Sb addition, the equilibrium phase expected to precipitate from supersaturated $\beta$-Sn is $\mathrm{Sb}_{3} \mathrm{Sn}_{4}$. However, calculated EBSD patterns of rhombohedral $\mathrm{SbSn}, \mathrm{Sb}_{3} \mathrm{Sn}_{4}$ and cubic NaCl-type $\mathrm{SbSn}$ are highly similar, which makes experimental EBSD patterns from this phase prone to orientation misindexing by cubic pseudosymmetry. Therefore, in this work, we do not distinguish between the closely related $\mathrm{SbSn}$ and $\mathrm{Sb}_{3} \mathrm{Sn}_{4}$ structures, and we simply refer to it as 'SbSn'.

For similar reasons, while $\mathrm{Cu}_{6} \mathrm{Sn}_{5}$ may be the lowtemperature superstructure-ordered monoclinic $\eta$ '$\mathrm{Cu}_{6} \mathrm{Sn}_{5}$ phase after extended thermal cycling at $-55 / 125^{\circ} \mathrm{C},{ }^{27,28}$ here EBSD patterns from this phase were indexed as the higher-symmetry parent hexagonal $\eta-\mathrm{Cu}_{6} \mathrm{Sn}_{5}$ structure ${ }^{29,30}$ (Table III).

\section{RESULTS AND DISCUSSION}

\section{Microstructures}

Figure 2 (middle) illustrates the whole 84CTBGA package sectioned along row $M$, as indicated in the schematic diagram by the white arrow. Please note, due to the package design features, there is no Si die above this row. A detailed description of the test vehicle can be found in. ${ }^{16}$

As can be seen from the upper part of Figs. 2 and 3 , after soldering (i.e. at 'time zero'), all joints studied in both packages contained a single grain of $\beta$-Sn in cross-sections, and it is likely that each is a $\beta$-Sn single crystal in three dimensions (3D). The single-grain joints are related to the high antimony addition and will be discussed in detail in a separate publication. This is quite different to $\mathrm{Sn}-\mathrm{Ag}-\mathrm{Cu}$ (without $\mathrm{Sb}$ ) joints where past work on similar packages has shown the $\beta$-Sn grain structure varies from joint to joint, including single-grain, beach ball and interlaced structures. ${ }^{1,17}$ In $\mathrm{Sn}-\mathrm{Ag}-\mathrm{Cu}$, these structures correlate, at least partially, with the nucleation undercooling for $\beta-\mathrm{Sn}^{34}$ and, therefore, depend on the package type and ball size, ${ }^{1}$ and substrate/surface finish used. ${ }^{35}$

Average misorientation (MO) maps for time-zero samples (i.e. Fig. 2c) show regions of $\beta$-Sn with moderate misorientation of up to $8^{\circ}-10^{\circ}$, mostly near the sample edges. This is probably mostly a sample preparation artefact, but stresses due to coefficient of thermal expansion (CTE) mismatch on cooling after soldering could also play a role, e.g. in joint \#11. ${ }^{16}$

The main $\beta$-Sn grain orientation formed during soldering is still visible in each joint after thermal cycling. For example, the lower part of Fig. 2 illustrates similar cross-sections in the 84CTBGA 

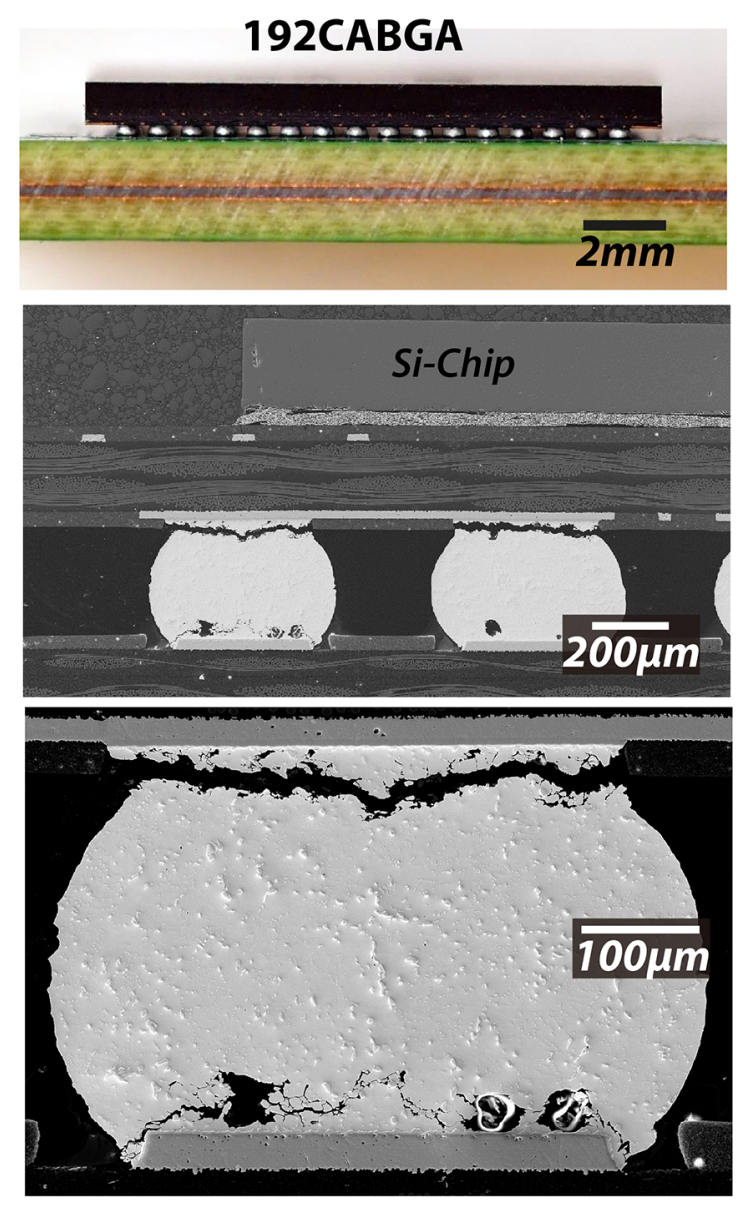

\section{CTBGA}
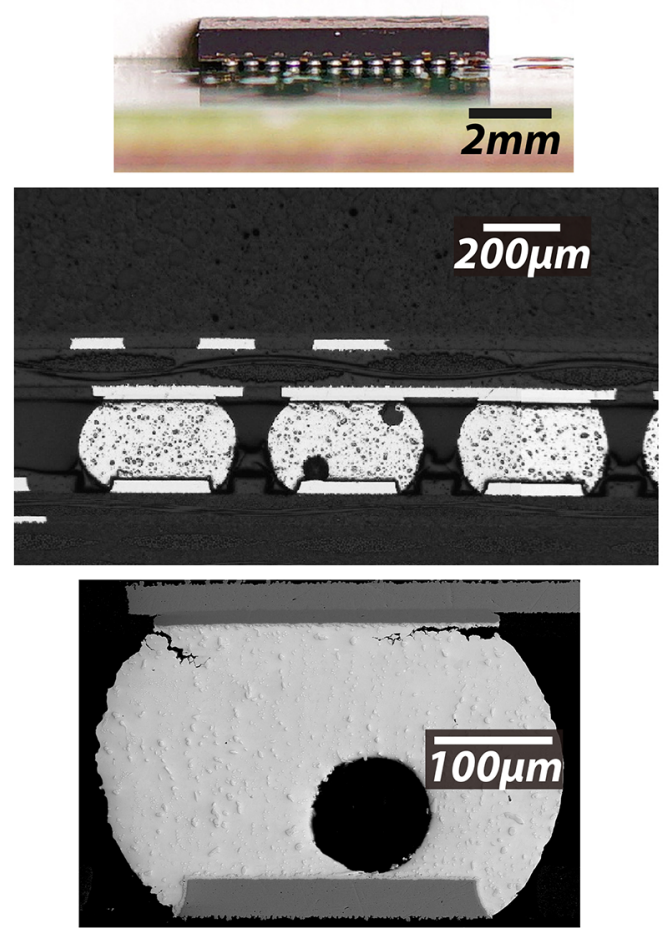

4Fig. 1. The 192CABGA (460 $\mu \mathrm{m}$ balls) and 84CTBGA (300 $\mu \mathrm{m}$ balls) daisy-chained components and cross-sections after thermal cycling.

package after 4876 thermal cycles. The accumulated damage can be observed as (i) substantial $\beta$-Sn misorientations both near the chip side and the PCB side, and (ii) localised $\beta$-Sn recrystallisation near the chip side. Red horizontal lines above the solder joints indicate the approximate crack length in these cross-sections.

After 4876 cycles, localised $\beta$-Sn misorientations developed in all joints, mostly near the component side and the PCB side. In contrast, localised $\beta$-Sn recrystallisation developed particularly near the component side in most joints. From the EBSD results in Fig. 2, there does not appear to be any simple correlation between the distance to the neutral point and the extent of recrystallisation or cracking in this row. For example, central joint \#7 is completely cracked and left-corner joint \#1 has only slight cracking (in this cross-section).

Figure 3 presents similar analysis results for the 192CABGA package sectioned along row $\mathrm{T}$, as indicated in the schematic diagram by the arrow. The 192CABGA package is characterised by a large die-to-package ratio, high strain and low CTE, ${ }^{16}$ which generates higher shear strains per cycle in its solder joints, even after accounting for the larger ball size (height) in the package. In contrast, the 84CTBGA has a smaller body size and smaller dieto-package ratio and, consequently, lower strain and smaller CTE mismatch. Therefore, it is expected that the thermal cycling behaviour and failure mode of these packages will differ, and past research has shown a substantial difference in performance in the same thermal cycling profile, with the 84CTBGA outperforming the 192CABGA. 1,16,36,37

The upper part of Fig. 3 illustrates solder joint cross-sections in the 192CABGA at 'time zero'. It can be seen that two joints (\#10 and \#11) have multiple grains (similar to that reported $i^{17}$ ), whereas the remaining joints have single-grain orientation of $\beta$-Sn in cross-sections. Overall, 19 out of 21 joints studied were single-grain in this 192 CABGA package.

As can be seen from Table I, the 192CABGA packages had the lower characteristic life and, being mounted on the same test vehicle, were continually cycled after failure until the higher-reliability 84CTBGA package failed. Therefore, the 192CABGA package had a higher degree of damage, which is overviewed in Fig. 3 (bottom). All joints cracked completely along the top (component side), and the corner joints cracked both along the component side and the PCB side. Red lines indicate the approximate extent of cracking. 
Table III. Crystallographic details of phases used for EBSD indexing, with references

\begin{tabular}{|c|c|c|c|c|c|c|c|c|c|c|c|}
\hline Phase & $\begin{array}{l}\text { Lattice } \\
\text { system }\end{array}$ & $\begin{array}{l}\text { Space } \\
\text { group }\end{array}$ & Cell setting & $\underset{[\stackrel{\mathbf{A}}{\mathbf{n}}]}{\mathbf{a}}$ & $\begin{array}{c}\mathbf{b} \\
{[\AA \mathbf{A}]}\end{array}$ & $\stackrel{\text { c }}{[\AA}$ & $\begin{array}{c}\alpha \\
{\left[{ }^{\circ}\right]}\end{array}$ & $\begin{array}{c}\beta \\
{\left[{ }^{\circ}\right]}\end{array}$ & $\begin{array}{c}\gamma \\
{\left[{ }^{\circ}\right]}\end{array}$ & Notes & Ref. \\
\hline $\mathrm{SbSn}$ & $\mathrm{Cub}$ & $\mathrm{Fm}$ & - & 6.092 & 6.092 & 6.092 & 90 & 90 & 90 & NaCl-type & 21 \\
\hline \multirow[t]{2}{*}{$\mathrm{SbSn}$} & Rhombohedral & $\mathrm{R}-3 \mathrm{~m}$ & Hexagonal & 4.325 & 4.325 & 5.338 & 90 & 90 & 120 & & 23 \\
\hline & & & Rhombohedral & 3.068 & 3.068 & 3.068 & 89.78 & 89.78 & 89.78 & 46 at. $\% \mathrm{Sb}$ & \\
\hline \multirow{2}{*}{$\mathrm{Sb}_{3} \mathrm{Sn}_{4}$} & Rhombohedral & $\mathrm{R}-3 \mathrm{~m}$ & Hexagonal & 4.331 & 4.331 & 37.302 & 90 & 90 & 120 & & 25 \\
\hline & & & Rhombohedral & $3.067^{\mathrm{a}}$ & $3.067^{\mathrm{a}}$ & $3.067^{\mathrm{a}}$ & 89.82 & 89.82 & 89.82 & 42 at.\% Sb & \\
\hline$\beta$-Sn & Tetr & $\mathrm{I} 4_{1} / \mathrm{amd}$ & - & 5.831 & 5.8308 & 3.181 & 90 & 90 & 90 & & 31 \\
\hline $\mathrm{Cu}_{6} \mathrm{Sn}_{5}$ & Hexagonal & $\mathrm{P}_{3} / \mathrm{mmc}$ & - & 4.192 & 4.192 & 5.037 & 90 & 90 & 120 & & 32 \\
\hline $\mathrm{Ag}_{3} \mathrm{Sn}$ & Orthorhombic & Pmmn & - & 5.968 & 4.78 & 5.184 & 90 & 90 & 90 & & 33 \\
\hline
\end{tabular}

${ }^{\text {a For }} \mathrm{Sb}_{3} \mathrm{Sn}_{4}$, the rhombohedral setting has been approximated using 1/7 of the c-axis from its hexagonal setting, following Schmetterer et al. ${ }^{25}$

Figure 4 presents examples of cracking on the component side in both packages. In the smaller package (84CTBGA with $300 \mu \mathrm{m}$ balls), cracking always occurred through the $\beta$-Sn phase (i.e. a solder fatigue mechanism). On the other hand, in the larger package (192CABGA with $460 \mu \mathrm{m}$ balls), most joints failed by crack growth through the $\beta$-Sn phase, although there was some evidence for mixedmode failures involving the $\mathrm{Cu}_{6} \mathrm{Sn}_{5}$ layer in some cases when the crack exposed the interface with $\mathrm{Cu}_{6} \mathrm{Sn}_{5}$ grains and propagated into the IMC layer.

Due to much higher levels of damage of BGA balls in the 192CABGA package, only five joints were studied here by EBSD. As can be seen in Fig. 3 (bottom), localised $\beta$-Sn recrystallisation developed particularly near the component side in all joints with exception of the corner joints (\#1 and \#16) where a significant damage with subsequent localised $\beta$-Sn recrystallisation also occurred on the PCB side. Since the damage of $\beta$-Sn in 192CABGA joints partially occurred after the joints had failed, this paper focuses primarily on microstructural evolution in the 84CTBGA with $300 \mu \mathrm{m}$ balls.

In the $84 \mathrm{CTBGA}$ package, different joints contained differing degrees of damage after 4876 thermal cycles (Fig. 2). Figure 5 uses three joints containing increasing degrees of accumulated damage to give a sense of microstructural evolution during thermal cycling. Please note that these are not identical joints experiencing the same strain per cycle shown at three different numbers of cycles and, therefore, caution is required with their interpretation. However, all joints in Fig. 2 contain the same general trends, and Fig. 5 gives a reasonable overview of the stages in damage evolution. Figure 5c and $d$ contains sporadic regions of localised lattice rotation and a few recrystallised grains near the component (top) side. Figure 5e and f contains a continuous region of high misorientation and more recrystallised grains near the component (top) side. Figure $5 \mathrm{~g}$ and $\mathrm{h}$ contains complete recrystallisation across the entire top of the joint and is cracked approximately $60 \%$ along the recrystallised region (Fig. 2). Figure $5 \mathrm{f}$ and $\mathrm{h}$ also have some regions of localised misorientation near the PCB (bottom) side, but this is significantly less than near the component (top) side. It can be inferred that in the earlier stages of damage evolution (Fig. 5c-f), the degree of misorientation and recrystallisation is greatest at the corners on the component side and, with continued damage development (Fig. $5 \mathrm{~g}$ and $\mathrm{h}$ ), this spreads across the entire top side of the joint.

Figure 6 shows a joint in the 84CTBGA package with localised recrystallisation and cracking $100 \%$ across the recrystallised region in more detail. The EBSD dataset was collected with smaller step size, and the $\mathrm{Ag}_{3} \mathrm{Sn}, \mathrm{SbSn}$ and $\mathrm{Cu}_{6} \mathrm{Sn}_{5}$ phases can be resolved in the phase map in Fig. 6c. The IPF map in Fig. 6d shows highly localised recrystallisation. In the EBSD quality map in Fig. 6e, it can be seen that multiple cracks have propagated along the network of grain boundaries created by recrystallisation. Further information can be seen in the misorientation map in Fig. $6 f$ where, between the recrystallised grains (red and other 'hot' colours) and the main parent grain beneath (dark blue), pale blue subgrains exist with low-angle boundaries to the parent grain.

Comparing the phase map in Fig. 6c with the IPF and misorientation maps in Fig. 6d and $\mathrm{f}$, it is clear that the $\mathrm{SbSn}$ (yellow) and $\mathrm{Ag}_{3} \mathrm{Sn}$ (green) particles are more coarsened in the region with localised recrystallisation and subgrains than in the low deformation centre of the joint. Note that this is not the case for $\mathrm{Cu}_{6} \mathrm{Sn}_{5}$ which are substantially larger in the low-deformation centre of the joint (and were presumably also substantially larger at time zero). The localised coarsening is quantified later in the paper using EBSD datasets with higher resolution.

Combining the development of damage in Fig. 5 with the fully cracked sample in Fig. 6, it can be concluded that the general sequence of events 


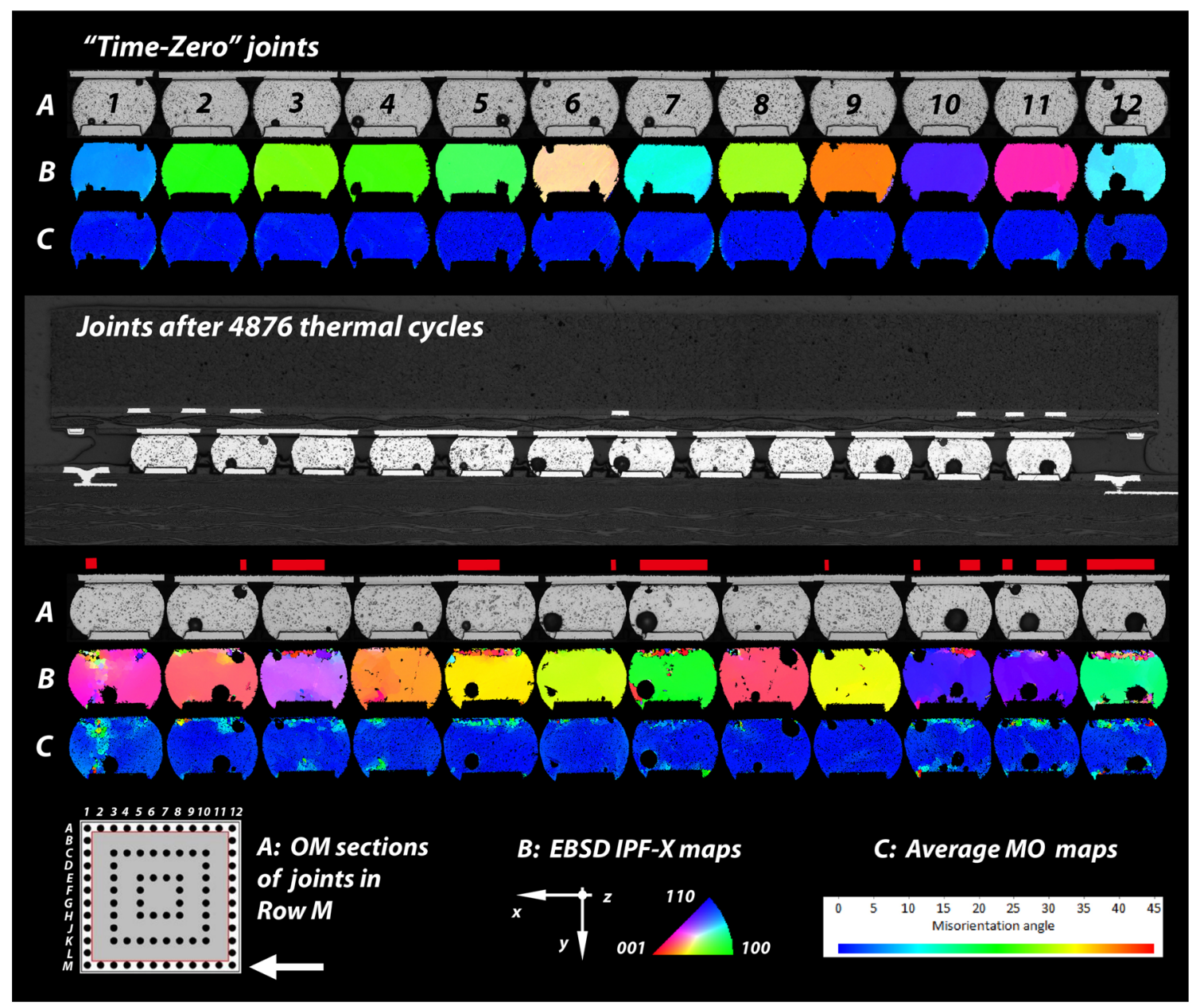

Fig. 2. 84CTBGA component sectioned along row $M$ (indicated by white arrow) at time zero and after 4876 thermal cycles. (a) Optical micrographs, (b) EBSD inverse pole figure (IPF)-X maps and (c) average misorientation (MO) maps.

leading to failure in the $\mathrm{Sn}-3.8 \mathrm{Ag}-0.9 \mathrm{Cu}-5.5 \mathrm{Sb}-0.5 \mathrm{In}$ joints studied here is similar to that deduced in Sn$\mathrm{Ag}-\mathrm{Cu}$ joints in past work. ${ }^{38-41}$ Specifically, localised lattice rotation, subgrain formation, coarsening of $\mathrm{Ag}_{3} \mathrm{Sn}$ particles, and recrystallisation of $\beta$-Sn all occur in areas of stress concentration near the component side where the local strain per cycle is highest. During continued temperature cycling, the recrystallised grain boundaries slide and grains rotate. Ultimately, $\operatorname{crack}(\mathrm{s})$ initiate and grow along the network of recrystallised grain boundaries to failure. The addition of $\mathrm{Sb}$ adds further features to these failure mechanisms, most notably with the precipitation and coarsening of SbSn particles. The next section considers SbSn in more detail.

\section{SbSn Precipitation and Coarsening}

The phase transformations involving SbSn that are likely to occur during soldering, room-temperature storage, and thermal cycling of Sn-3.8Ag$0.9 \mathrm{Cu}-5.5 \mathrm{Sb}$ are summarized in Fig. 7.

Figure $7 \mathrm{a}$ is a plot of the composition of the $\beta$-Sn and liquid phases near the end of solidification from the Scheil model in Thermo-Calc TCSLD3.1. It shows the micro-segregation profile in Sn-3.8Ag$0.9 \mathrm{Cu}-5.5 \mathrm{Sb}$ (wt.\%) for the case of zero diffusion in the solid. Note that the formation of $\mathrm{Ag}_{3} \mathrm{Sn}$ and $\mathrm{Cu}_{6} \mathrm{Sn}_{5}$ was included in the calculation but are not plotted in Fig. 7a. It can be seen that, at $\beta-\mathrm{Sn}+\mathrm{L}$ interfaces, $\mathrm{Sb}$ partitions to the $\beta$-Sn phase $\left(\mathrm{k}_{\mathrm{Sb}}>1\right)$, whereas $\mathrm{Ag}$ and $\mathrm{Cu}$ partition to the liquid $\left(\mathrm{k}_{\mathrm{Cu}}\right.$ and $\mathrm{k}_{\mathrm{Ag}}<1$ ). $\mathrm{k}$ is the partition coefficient defined as $k=$ $C_{s}^{*} / C_{L}^{*}$ where the * indicates local equilibrium at the interface. Since the partition coefficient for $\mathrm{Ag}$ and $\mathrm{Cu}$ is near zero $(\mathrm{k}<0.008)$, there is negligible solubility for $\mathrm{Ag}$ and $\mathrm{Cu}$ in $\beta$-Sn, and rejected $\mathrm{Ag}$ and $\mathrm{Cu}$ in the liquid becomes $\mathrm{Ag}_{3} \mathrm{Sn}$ and $\mathrm{Cu}_{6} \mathrm{Sn}_{5}$ by eutectic reactions. Since $\mathrm{Sb}$ has $\mathrm{k}>1(\mathrm{k} \sim 1.2)$, the $\mathrm{Sb}$ content is higher in $\beta$-Sn than the liquid, and there is 'inverse coring' with maximum $\mathrm{Sb}$ content in the first $\beta$-Sn to form. Thus, more $\mathrm{Sb}$ is expected at the centre of $\beta$-Sn dendrites than in $\beta$-Sn in eutectic regions.

During solidification of $\mathrm{Sn}-3.8 \mathrm{Ag}-0.9 \mathrm{Cu}-5.5 \mathrm{Sb}-$ $0.5 \mathrm{In}$, the SbSn phase is not calculated to form for either equilibrium or Scheil solidification conditions. Instead, SbSn forms by solid-state 


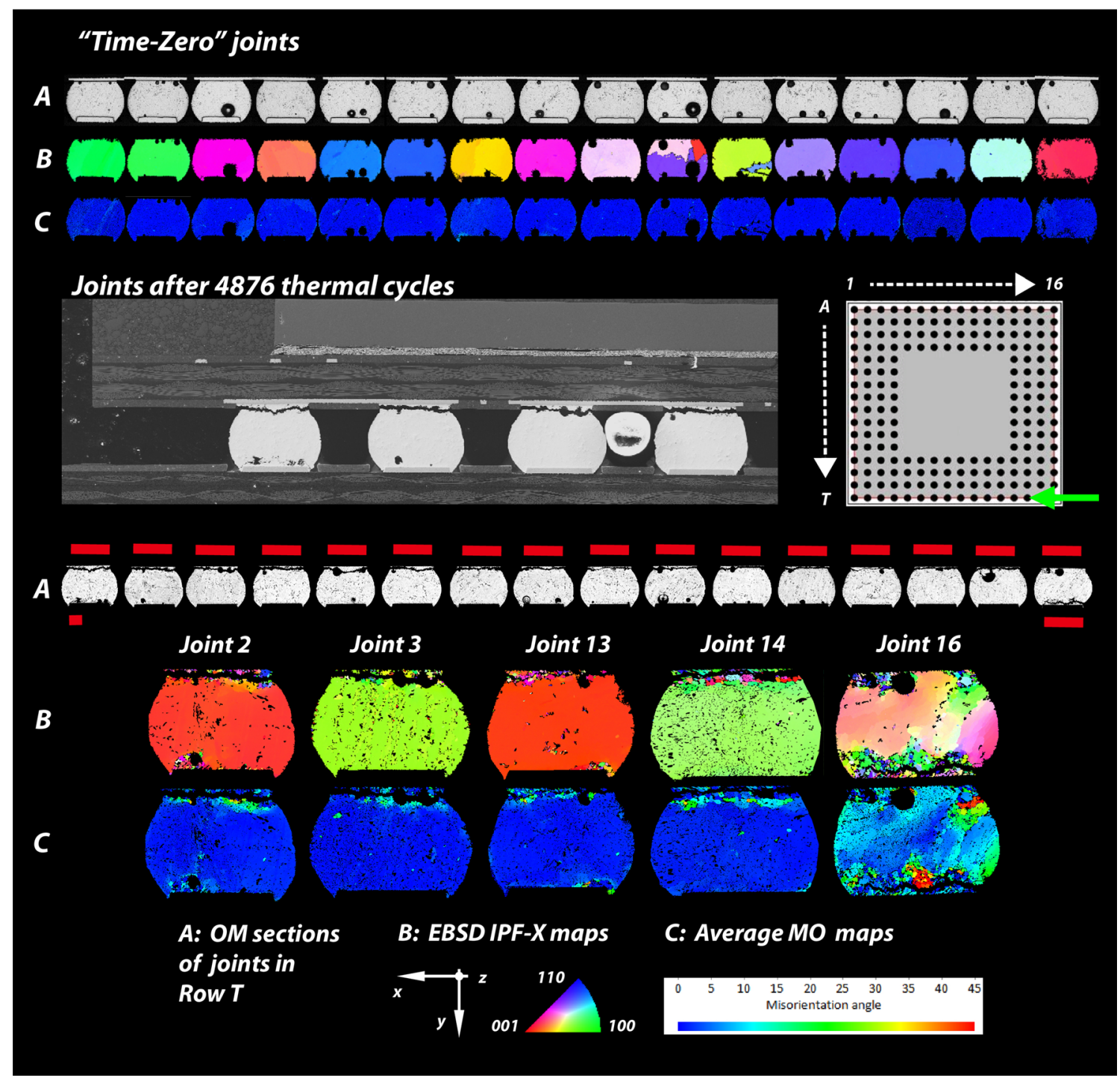

Fig. 3. 192CABGA component sectioned along row $\mathrm{T}$ (indicated by green arrow) at time zero and after 4876 thermal cycles. (a) Optical micrographs, (b) EBSD IPF-X maps and (c) average misorientation (MO) maps.

precipitation in $\beta$-Sn due to the temperature-dependent retrograde solvus line shown in the isopleth in Fig. 7b. Thus, on cooling after solidification, the $\beta$ $\mathrm{Sn}$ phase becomes supersaturated in $\mathrm{Sb}$, and there is a driving force to precipitate $\mathrm{SbSn}$ during roomtemperature storage and thermal cycling. Since the first $\beta$-Sn to form during solidification had the highest $\mathrm{Sb}$ content, the centre of dendrites have the higher driving force for $\mathrm{SbSn}$ precipitation and should form a higher volume fraction of SbSn phase than interdendritic eutectic $\beta$-Sn. This is consistent with the larger amount of SbSn cuboids in $\beta$-Sn away from eutectic regions in Figs. 7c and 8c.

In the range of $-55^{\circ} \mathrm{C}$ to $125^{\circ} \mathrm{C}$, the equilibrium volume fraction of $\mathrm{SbSn}$ phase varies from $\sim 11$ vol. $\%$ at $125^{\circ} \mathrm{C}$ to $\sim 12$ vol. $\%$ at $-55^{\circ} \mathrm{C}$ according to the calculations in Fig. $7 \mathrm{~b}$, and the $\beta$-Sn solvus at 5.5 wt. $\% \mathrm{Sb}$ is $\sim 204^{\circ} \mathrm{C}$. Therefore, once fully precipitated, the volume fraction $\mathrm{SbSn}$ particles are not be expected to change significantly during thermal cycling.

Figure 8 shows typical regions of microstructure containing SbSn precipitates at a range of magnifications. It can be seen that the localised $\beta$-Sn recrystallisation zone (i.e. areas around the crack in Fig. $8 b$ ) contain $\beta$-Sn grains that are virtually $\mathrm{SbSn}$ precipitate-free, and the majority of SbSn particles are found at the recrystallised $\beta$-Sn grain boundaries in this area. Moving further down into the bulk of the solder joint, i.e. into the low-deformation regions shown Fig. 8c, SbSn particles are found mostly within the $\beta$-Sn dendrites rather than in eutectic regions containing $\mathrm{Ag}_{3} \mathrm{Sn}$ and $\mathrm{Cu}_{6} \mathrm{Sn}_{5}$, which is consistent with the thermodynamic calculations in Fig. 7.

As can be inferred from Fig. 8c, after thermal cycling, SbSn precipitates were generally smaller than $\mathrm{Ag}_{3} \mathrm{Sn}$. Particle size analysis with ImageJ 


\section{CABGA}

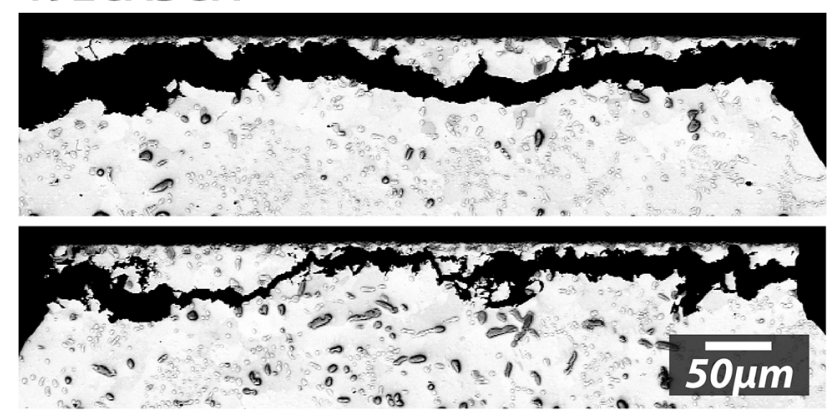

\section{CTBGA}

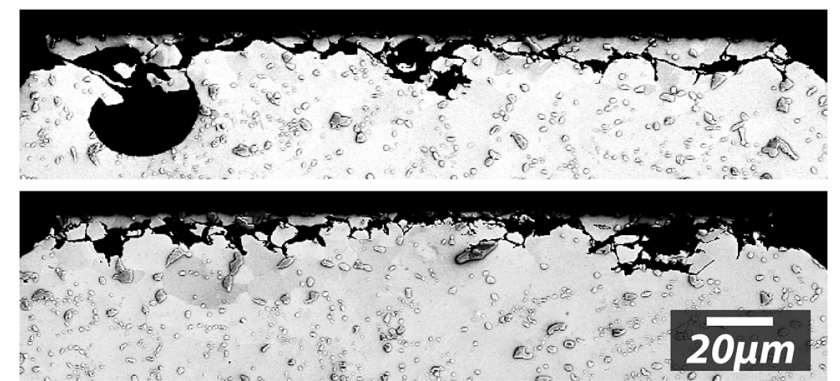

Fig. 4. Typical cracking on the component side in 84CTBGA and 192CABGA packages after thermal cycling.

produced the following results: for the areas shown in Fig. 8, the mean SbSn cuboid width was 0.41 $( \pm 0.19) \mu \mathrm{m}$, whereas the mean $\mathrm{Ag}_{3} \mathrm{Sn}$ size (equivalent diameter $)$ was $1.72( \pm 0.74) \mu \mathrm{m}$. These submicrometre $\mathrm{SbSn}$ precipitates provide a second population of strengthening particles.

It is known that, in $\mathrm{Sn}-\mathrm{Ag}-\mathrm{Cu}$ solders, Orowan strengthening from $\mathrm{Ag}_{3} \mathrm{Sn}$ particles is a key contributor to creep strength and thermal fatigue performance, ${ }^{42-44}$ and the higher volume fraction of $\mathrm{Ag}_{3} \mathrm{Sn}$ particles is thought to be the main factor behind the improved thermal fatigue performance of SAC305 over SAC105. ${ }^{1}$ The $\mathrm{Ag}_{3} \mathrm{Sn}$ particles that provide strengthening originally formed in eutectic reactions during solidification and then changed morphology during coarsening. They are, therefore, located in the eutectic regions between $\beta$-Sn dendrites, which generates significant local differences in the creep response of these two regions in Sn-Ag$\mathrm{Cu}$ solders. ${ }^{45}$ The large primary $\mathrm{Ag}_{3} \mathrm{Sn}$ plates that sometimes form before $\beta$-Sn nucleation play a less clear role in reliability ${ }^{46-49}$ but tie up Ag that could otherwise have formed eutectic $\mathrm{Ag}_{3} \mathrm{Sn}$ and put an upper limit on the $\mathrm{Ag}$ content used in $\mathrm{Sn}-\mathrm{Ag}-\mathrm{Cu}-$ based solders.

In contrast, with $\mathrm{Sb}$ additions, $\mathrm{SbSn}$ precipitates in the solid state and is located within $\beta$-Sn dendrites where the Sb content was highest at the end of solidification. Thus, $\mathrm{Ag}_{3} \mathrm{Sn}$ particles strengthen eutectic $\beta$-Sn, and SbSn particles strengthen the dendritic $\beta$-Sn, and this combination is likely to be largely responsible for the improved reliability in thermal cycling (Table I). Sb may also provide some solid solution strengthening, especially in the early stages of thermal cycling before SbSn fully precipitates out from the supersaturated $\beta$-Sn phase, and above $\sim 50^{\circ} \mathrm{C}$ where Fig. $7 \mathrm{~b}$ indicates that the solubility for $\mathrm{Sb}$ in $\beta$-Sn increases above near zero.

The highly faceted shape of SbSn particles in Fig. 8 suggested preferred interfaces with $\beta$-Sn, which were further explored. The EBSD investigation summarized in Fig. 9 revealed that the cuboidal morphology of SnSn particles in $\beta$-Sn was accompanied by a simple and consistent orientation relationship. Figure $9 \mathrm{a}$ is a typical region of $\beta$-Sn containing SbSn precipitates. Figure 9b is an EBSD phase map, and Fig. 9c shows selected pole figures of $\beta$-Sn and SbSn from this region containing multiple SbSn particles. For the $\beta$-Sn pole figures, the presence of two spots in the $\{100\}$ and one spot in the $\{001\}$ indicates a single grain (orientation). For the SbSn pole figure, the presence of three spots in the $\{100\}$ indicates that all SnSn precipitates have the same orientation. From this, the orientation relationship (OR) can be written as Eq. 1.

$$
(100)_{\beta S n} \|(100)_{\mathrm{SbSn}} \text { and }[001]_{\beta \mathrm{Sn}} \|[001]_{\mathrm{SbSn}}
$$

This simple OR can be understood in terms of (i) the lattice parameters of $\beta$-Sn and SbSn differing by only $\sim 5 \%$ and $\sim 4 \%$ for $\mathrm{a}_{\mathrm{Sn}} / 2 \mathrm{a}_{\mathrm{SbSn}}$ and $\mathrm{c}_{\mathrm{Sn}} / \mathrm{c}_{\mathrm{SbSn}}$, respectively (Table III) using the rhombohedral cell setting for $\mathrm{SbSn}$; and (ii) the similar distorted octahedral coordination in both phases. ${ }^{25}$ The planar lattice match for the plane shown in Eq. 1 is plotted in Fig. 9d using $2 \times 2$ unit cells of $\mathrm{SbSn}$ (rhombohedral setting) and $1 \times 2$ unit cells of $\beta$-Sn. The average atomic disregistry along the three red vectors is $\sim 4 \%$. The OR in Eq. 1 was found to be consistent across multiple samples and regions. To quantify this, the $\{100\}$ of $247 \mathrm{SbSn}$ particles in Fig. 9b have been plotted into the tetragonal $\beta$-Sn inverse pole figure in Fig. 9e. The average misorientation is less than $1^{\circ}$ for both $\{100\} \beta_{\mathrm{Sn}}$ and $\{001\} \beta_{\text {Sn }}$.

Examining the two-dimensional (2D) sections in Figs. 7c, 8c and 9a, it can be seen that the shape of SbSn precipitates is consistent with cuboids rather than cubes. The EBSD phase maps in Fig. 9f give examples of cuboidal precipitates where the unit cell wireframe orientations have been plotted from the measured Euler angles. It can de deduced that the elongated direction of $\mathrm{SbSn}$ is along the c-direction of $\beta$-Sn (the short direction in the $\beta$-Sn unit cell). The preferred growth of precipitates along the cdirection in $\beta$-Sn has been previously reported for SbSn phase ${ }^{50}$ as well as for (Bi) phase. ${ }^{51}$ One of the underlying reasons for this preferred growth direction might be that [001] is the fastest diffusion direction in the $\beta$-Sn crystal for a number of solute elements such as $\mathrm{Cu}, \mathrm{Ni}, \mathrm{Ag}$ and $\mathrm{Au} .{ }^{52-54}$ McCabe et al. have previously explored the precipitation of 

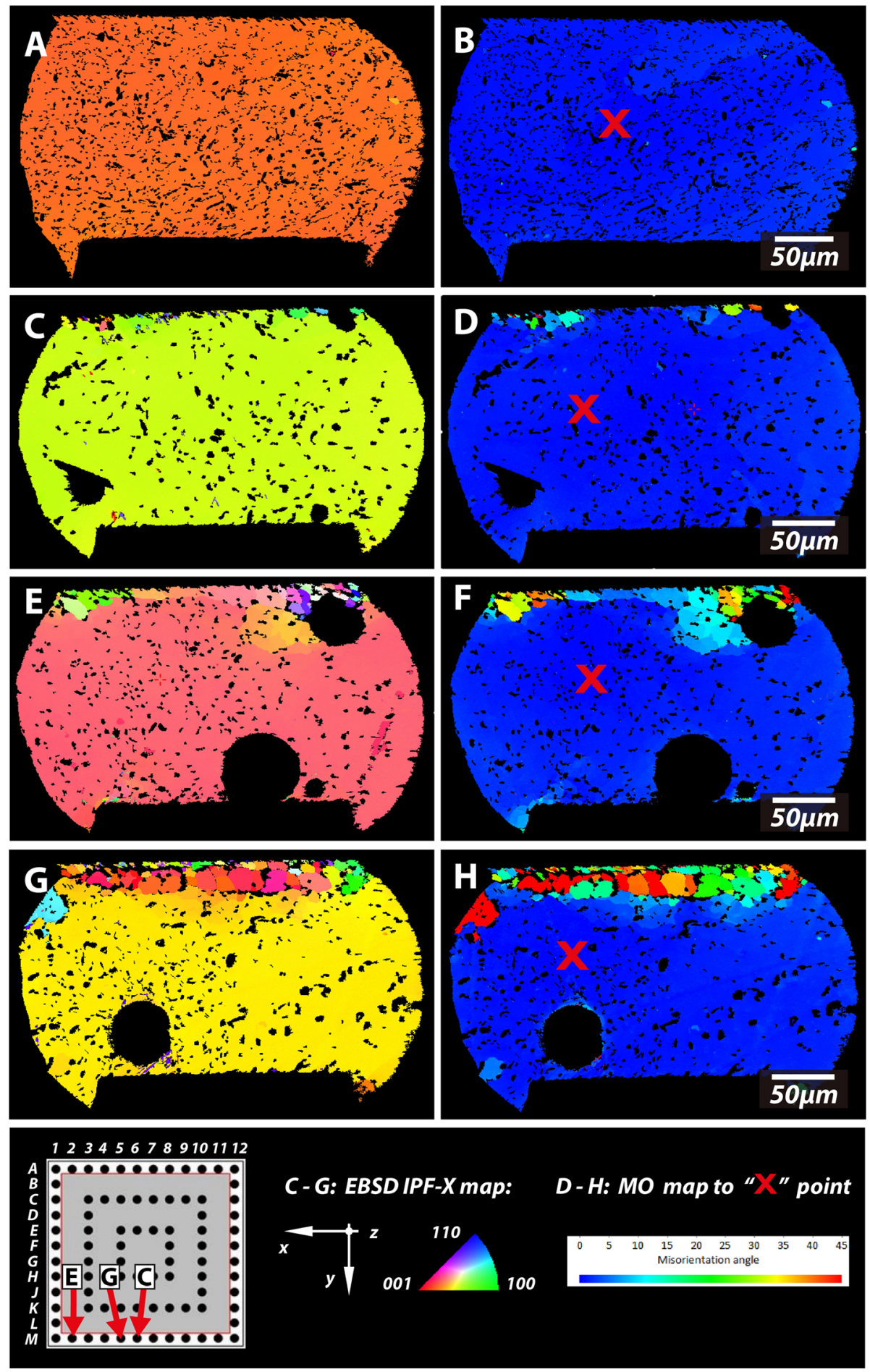

Fig. 5. Joints with different degrees of damage in the 84CTBGA package. (a-b) Time-zero joint and (c-h) joints after thermal cycling. Left: EBSD IPF-X maps. Right: Misorientation maps with respect to the red X. 

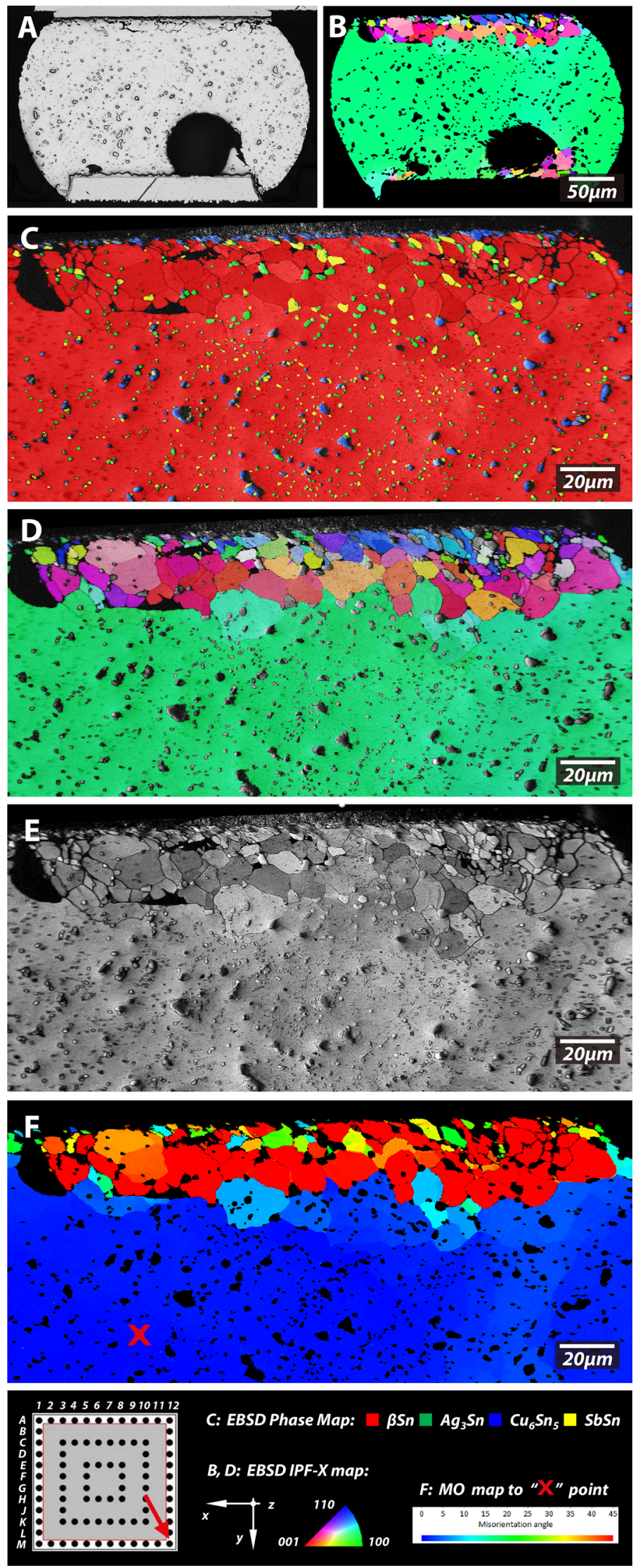

Fig. 6. Microstructure of a fully cracked joint from the 84CTBGA package. (a) Optical micrograph. (b, d) EBSD IPF-X map. (c) Phase map. (e) Quality map. (f) Misorientation map to the red ' $\mathrm{X}$ ' (Color figure online). 

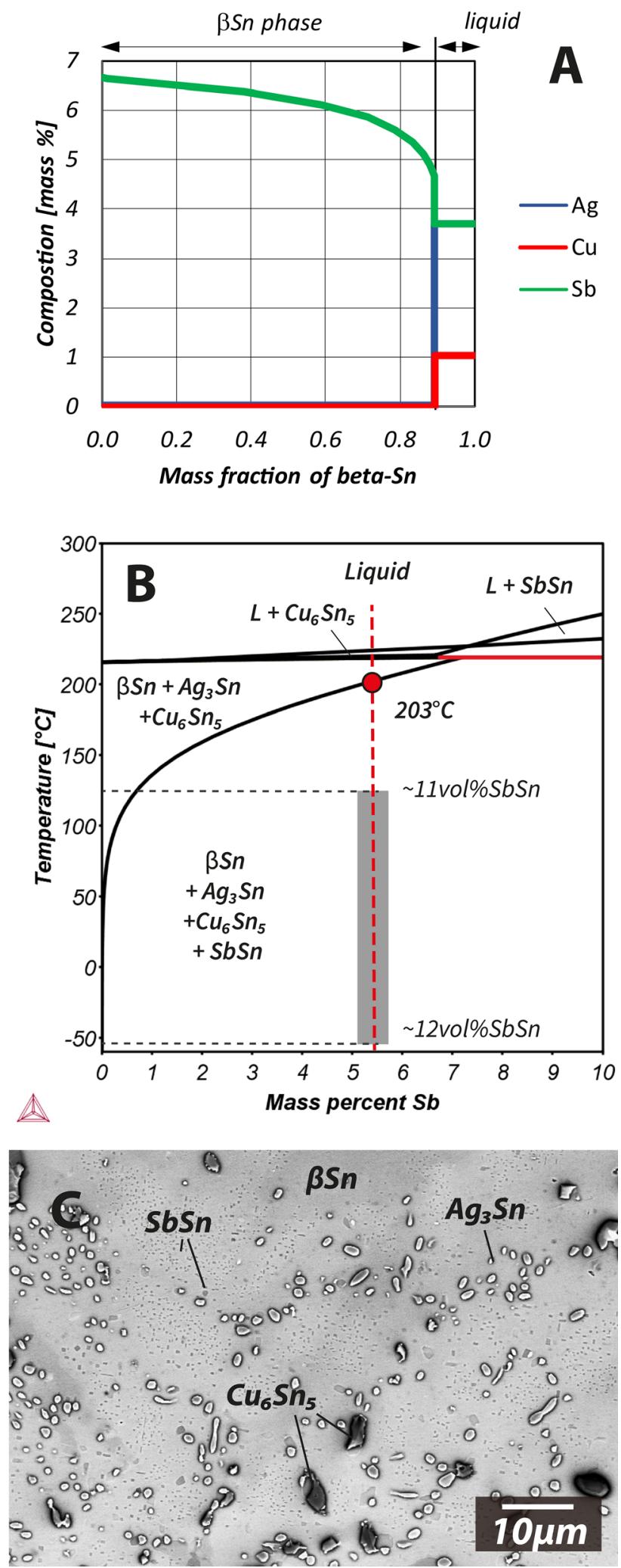

Fig. 7. (a, b) Plotted using data from Thermo-Calc TCSLD3.1. (a) Composition of the $\beta$-Sn and liquid near the end of solidification from the Scheil model for Sn-3.8Ag-0.9Cu-5.5Sb. (b) 95.3-xSn-3.8Ag$0.9 \mathrm{Cu}-\mathrm{xSb}$ isopleth (wt.\%). (c) Typical region of microstructure near the centre of a solder joint.
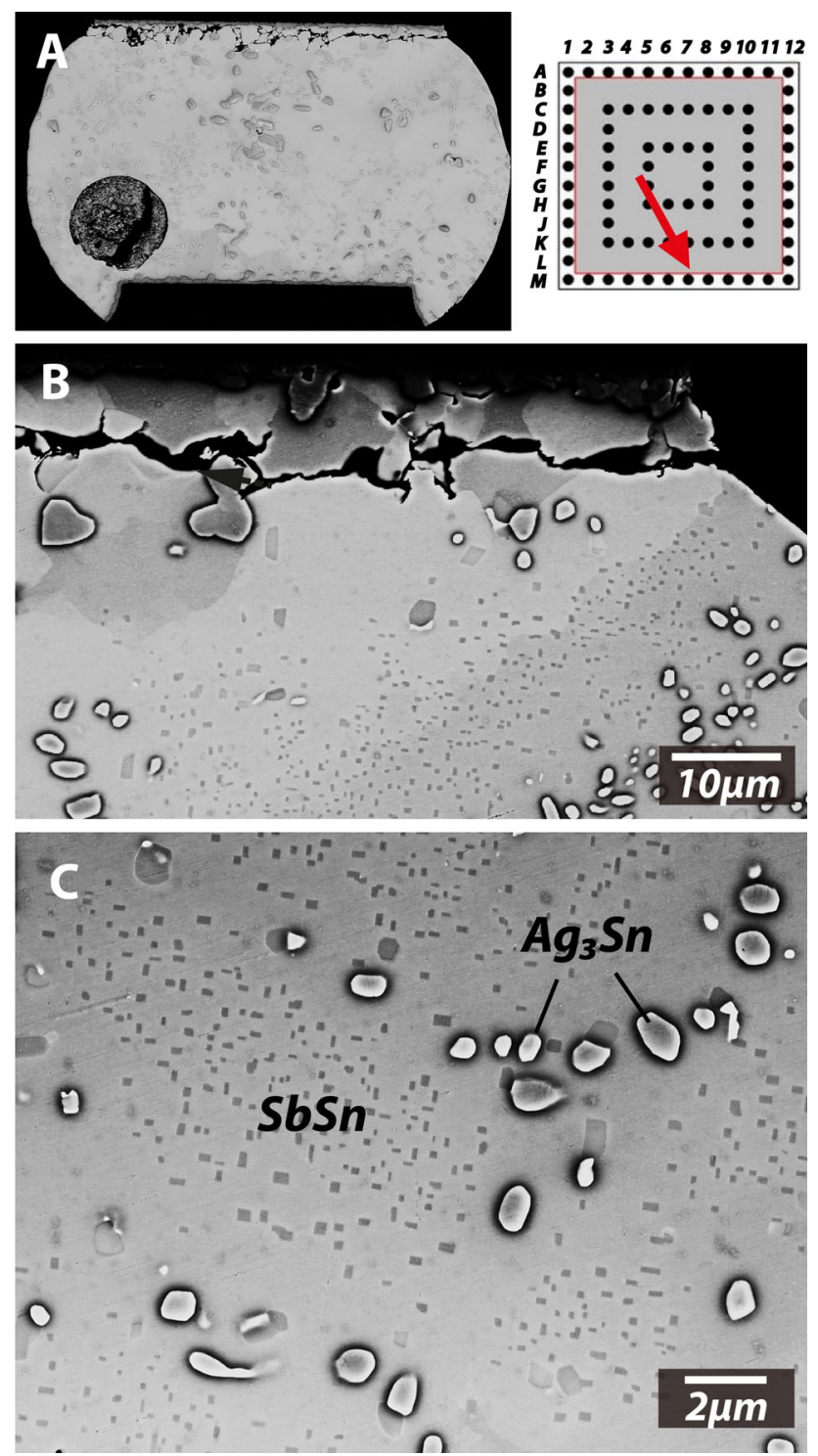

Fig. 8. SbSn precipitates at a range of magnifications (84CTBGA joint).

rectangular nano-whiskers of $\mathrm{SbSn}$ phase $(\sim 126 \mathrm{~nm} \times 126 \mathrm{~nm} \times 3-5 \mu \mathrm{m})$ in $\mathrm{Sn}-5.8$ wt. $\% \mathrm{Sb}$ and Sn-8.1 wt.\%Sb specimens quenched and heattreated at room temperature. ${ }^{50}$ These whiskers were observed in transmission electron microscopy (TEM) samples and were found to grow along either [001] or $<101>$ directions in the $\beta$-Sn matrix in approximately equivalent volume fractions in the five directions. Heat treatment of the most Sb-rich samples $(8.1 \mathrm{wt} . \% \mathrm{Sb})$ at $100^{\circ} \mathrm{C}$ resulted in a rapid coarsening behaviour with reduction of the aspect ratio of the precipitates whilst maintaining their submicron size. During the EBSD investigations in the present study, SbSn particles were only observed to grow along the c-direction in the $\beta$-Sn matrix, producing only one OR.

In addition to the copious formation of $\mathrm{SbSn}$ precipitates inside the $\beta$-Sn dendrites, it was also 

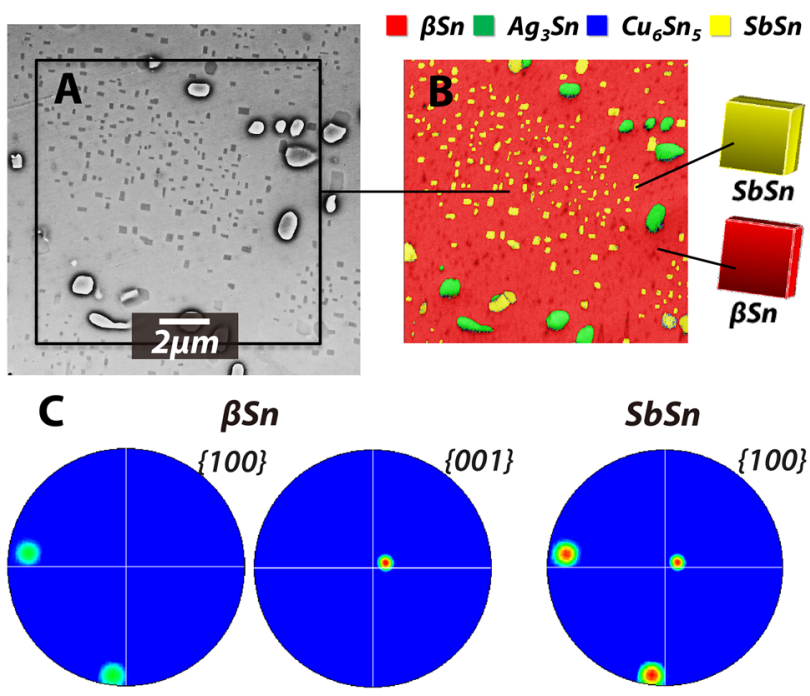

(100)Sn // (100)SbSn and [001] Sn // [001]SbSn

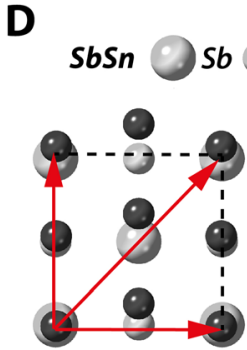

$\delta \sim 4.0 \%$

$\mathbf{F}$
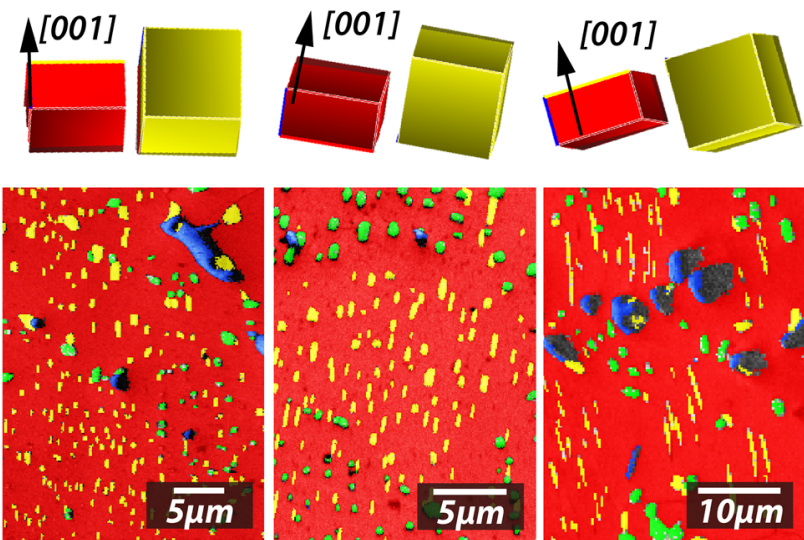

\section{$\beta S n \square \mathrm{Ag}_{3} \mathrm{Sn} \square \mathrm{Cu}_{6} \mathrm{Sn}_{5} \square \mathrm{SbSn}$}

Fig. 9. Orientation relationship (OR) between $\beta$-Sn and $\mathrm{SbSn}$ precipitates. (a) SEM image. (b, f) EBSD phase maps. (c) Pole figures from the region in (b). (d) Lattice match for the OR in (c). (e) The $\{100\}$ of $247 \mathrm{SbSn}$ particles plotted in the IPF of $\beta$-Sn.

common for some SbSn particles to share an interface with $\mathrm{Cu}_{6} \mathrm{Sn}_{5}$, and here too, a consistent $\mathrm{OR}$ was measured. Figure 10 shows a typical example. The EBSD phase map overlaid on the quality map contains a relatively large non-cuboidal SbSn particle (yellow) touching a $\mathrm{Cu}_{6} \mathrm{Sn}_{5}$ particle (blue). A
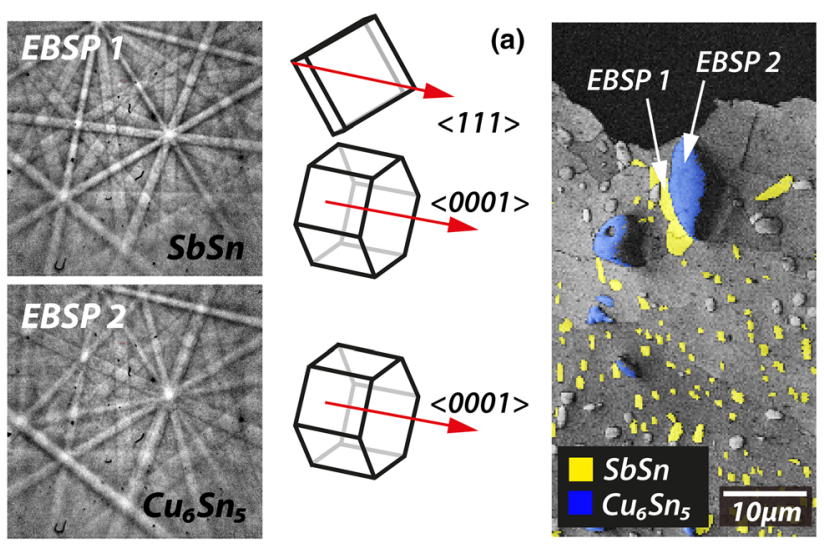

(b)

(c)
$\{11-20\} \mathrm{Cu}_{6} \mathrm{Sn}_{5} / /\{11-20\} \mathrm{SbSn}$

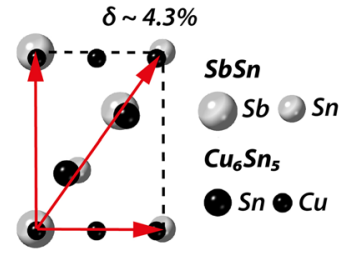

$\{10-10\} \mathrm{Cu}_{6} \mathrm{Sn}_{5} / /\{10-10\} \mathrm{SbSn}$

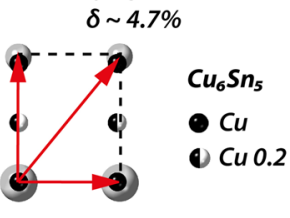

$\{0001\} \mathrm{Cu}_{6} \mathrm{Sn}_{5} / /\{0001\} \mathrm{SbSn}$ $\delta \sim 2.8 \%$
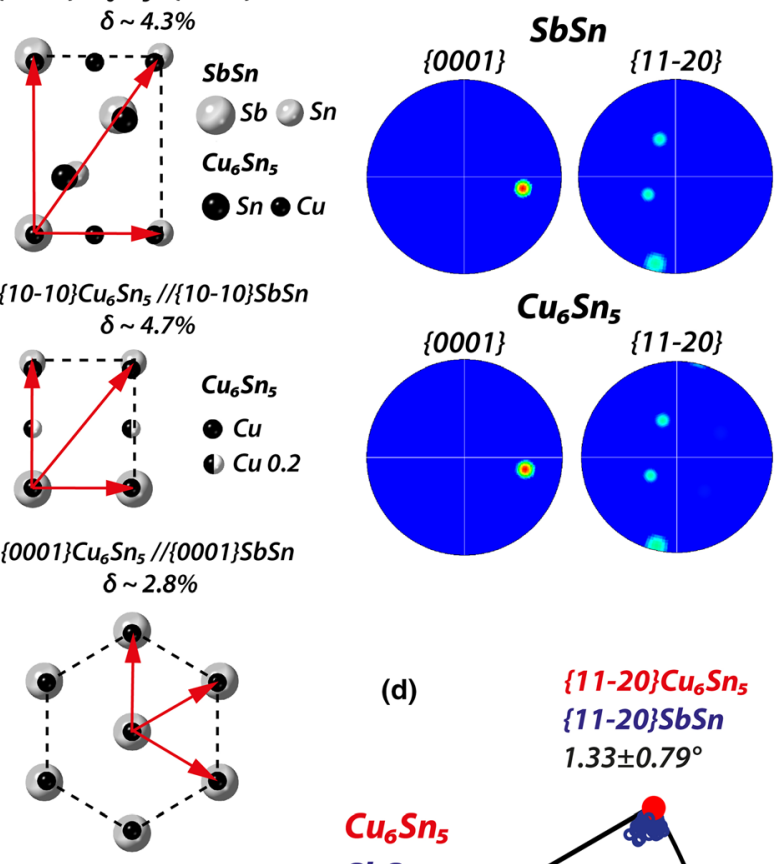

$\{11-20\}$
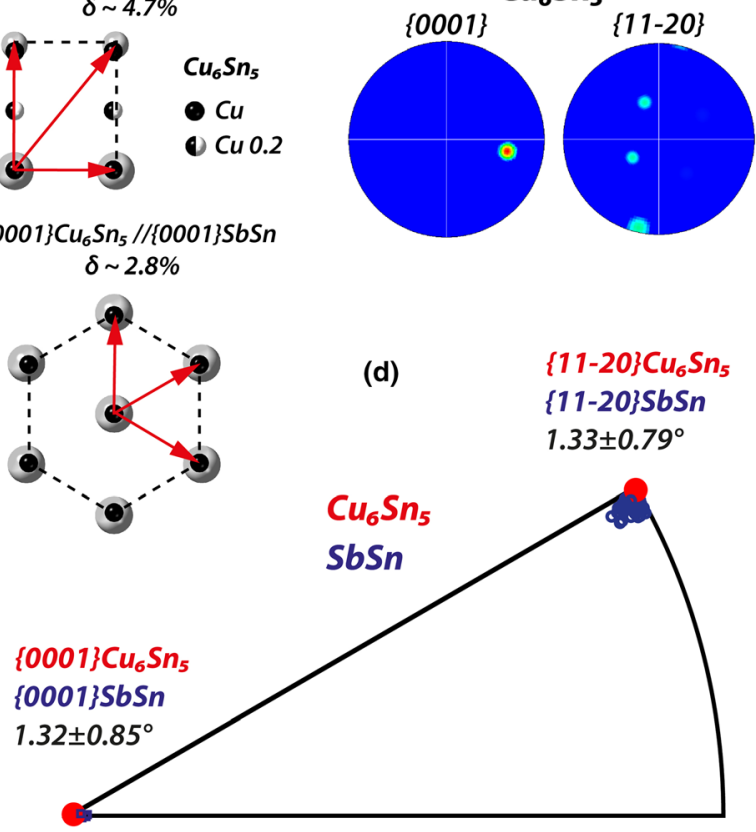

Fig. 10. Orientation relationship (OR) between $\mathrm{Cu}_{6} \mathrm{Sn}_{5}$ and $\mathrm{SbSn}$ precipitates. (a) EBSPs from the indicated regions of the EBSD phase map. Unit cell wireframes plotted from the measured Euler angles. (c) Pole figures from the same region. (b) The lattice match for three parallel planes in the OR. (d) The $\{0001\}$ of $37 \mathrm{SbSn}$ particles plotted in the IPF of $\beta$-Sn.

Kikuchi pattern (electron backscatter diffraction patterns, EBSP) from each of these particles is shown where various near-parallel bands (planes) and zone axes (directions) can be seen. The orientations of the unit cell wireframes are plotted from the Euler angles measured from Hough transform- 
Fig. 11. A region containing differing levels of localised damage in a joint from the 192CABGA component. (a) Backscattered electron (BSE) image. (b) EBSD phase map and the orientation relationship between three $\mathrm{SbSn}$ particles and their surrounding $\beta$-Sn. (c) IPF-X map of $\beta$-Sn. (d) Misorientation map of $\beta$-Sn.

based auto-indexing. For SbSn, the wireframes are plotted for both the rhombohedral cell setting (which appears almost cubic since $\alpha=89.8^{\circ}$ (Table III)) and the hexagonal cell setting. When viewed like this, there is a clear simple orientation relationship between the hexagonal wireframes, which can be further seen in the pole figures. The OR can be written as Eqs. $2 \mathrm{a}$ and $2 \mathrm{~b}$ using the rhombohedral and hexagonal cell settings, respectively, for SbSn.

$$
(11 \overline{2} 0)_{\mathrm{Cu} 6 \mathrm{Sn} 5} \|(110)_{\mathrm{SbSn}} \text { and }[0001]_{\mathrm{Cu} 6 \mathrm{Sn} 5} \|[111]_{\mathrm{SbSn}}
$$

$(11 \overline{2} 0)_{\mathrm{Cu} 6 \mathrm{Sn} 5} \|\{11 \overline{2} 0\}_{\mathrm{SbSn}}$ and $[0001]_{\mathrm{Cu} 6 \mathrm{Sn} 5} \|[0001]_{\mathrm{SbSn}}$

To quantify the reproducibility of this OR, the $\{0001\}$ and $\{11 \overline{2} 0\}$ of $37 \mathrm{SbSn}$ particles sharing a common interface with $\mathrm{Cu}_{6} \mathrm{Sn}_{5}$ have been plotted into the hexagonal $\mathrm{Cu}_{6} \mathrm{Sn}_{5}$ inverse pole figure in Fig. 10. The average misorientation is less than $2^{\circ}$ for both plane families.

Atomic matching for three parallel planes within this OR are plotted in Fig. 10. The best planar match is for the basal plane, where the mismatch is $\sim 3 \%$. However, it is unusual for $\mathrm{Cu}_{6} \mathrm{Sn}_{5}$ to have (0001) facets, ${ }^{55}$ and it is more likely that $\mathrm{SbSn}$ nucleates on the common $\{11 \overline{2} 0\}$ or $\{1 \overline{1} 00\}$ facets of $\mathrm{Cu}_{6} \mathrm{Sn}_{5}$ where the atomic mismatch is still better than $5 \%$.

The SbSn particle indicated in Fig. 10 shares an interface with both $\mathrm{Cu}_{6} \mathrm{Sn}_{5}$ and $\beta$-Sn, and it only has a simple OR with the $\mathrm{Cu}_{6} \mathrm{Sn}_{5}$. The shape of the $\mathrm{SbSn}$ interface with $\beta$-Sn for this particle is not a welldefined plane but a curved, presumably incoherent interface. This SbSn particle is significantly larger than the cuboidal SbSn particles elsewhere in this EBSD map. Since the coarsening rate of a particle increases with increasing interfacial energy with the matrix,${ }^{56,57}$ it is probable that the incoherent $\beta$ $\mathrm{Sn} / \mathrm{SbSn}$ interfaces of SbSn particles that nucleated on $\mathrm{Cu}_{6} \mathrm{Sn}_{5}$ are more prone to coarsening than the $\beta$ $\mathrm{Sn} / \mathrm{SbSn}$ cuboidal interfaces that formed through $\mathrm{SbSn}$ nucleation in $\beta$-Sn with a minimised interfacial energy.

\section{Interactions Between the SbSn Precipitates and Failure Mechanisms}

To better understand (i) the spatial distribution of SbSn particles with ORs to $\beta$-Sn and to $\mathrm{Cu}_{6} \mathrm{Sn}_{5}$, (ii)
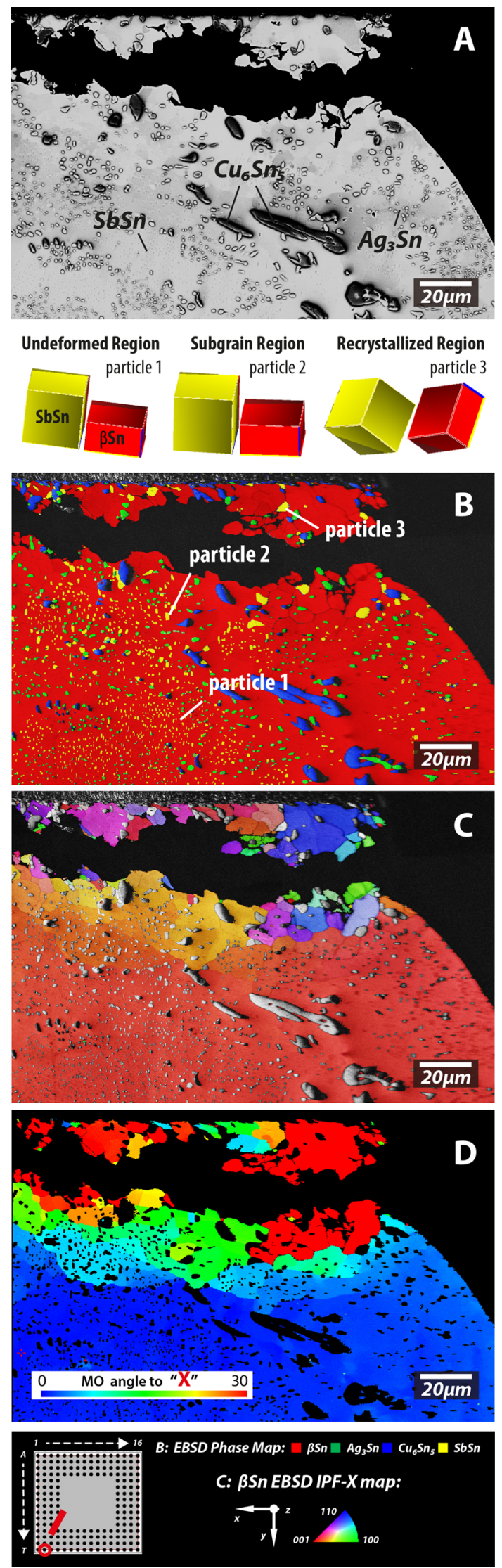

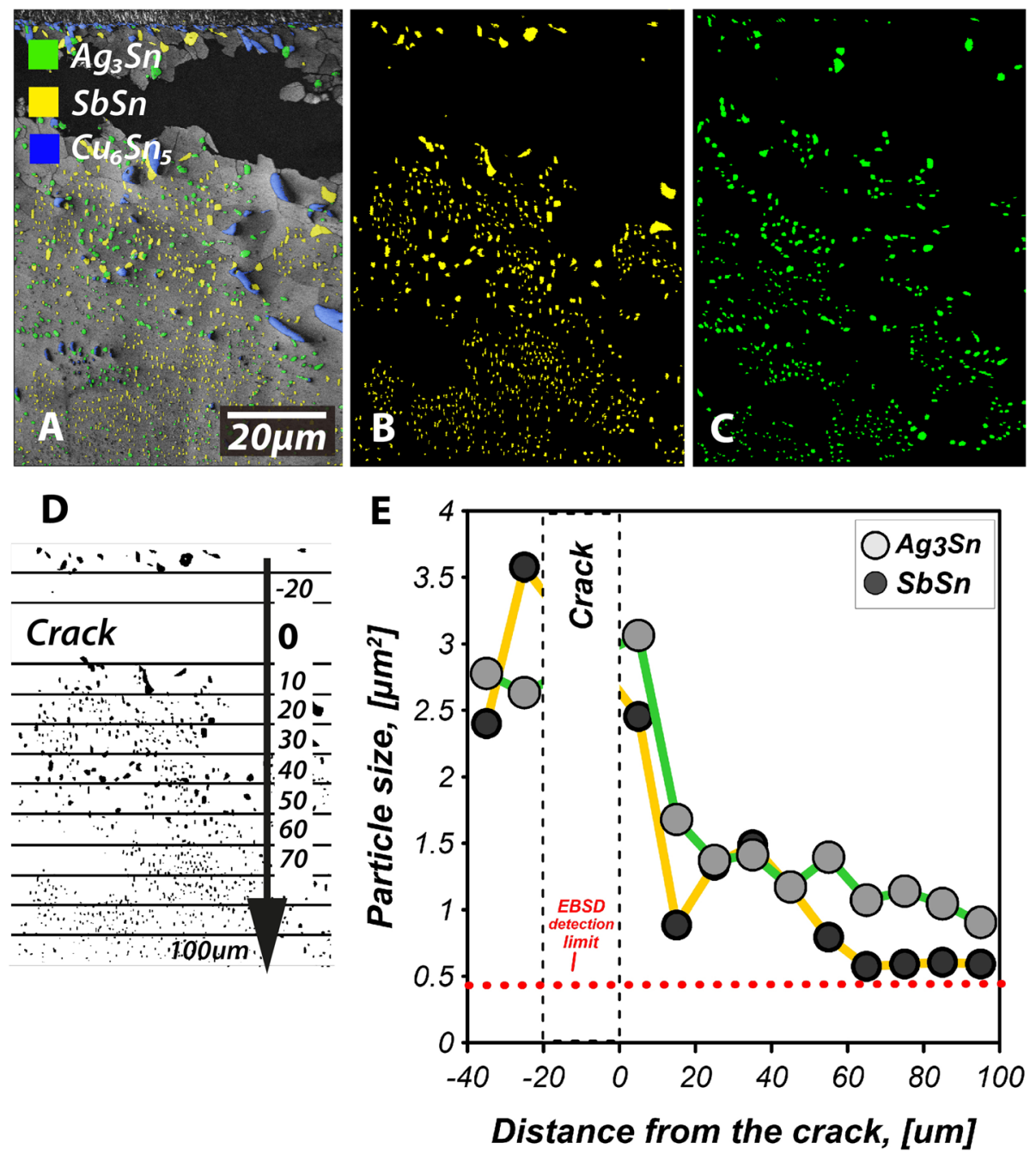

Fig. 12. Quantification of localised coarsening of $\mathrm{Ag}_{3} \mathrm{Sn}$ and $\mathrm{SbSn}$ in the area in Fig. 11. (a) EBSD phase map (excluding $\beta$-Sn) overlaid on the pattern quality map. (b) SbSn map. (c) $\mathrm{Ag}_{3} \mathrm{Sn}$ map. (d) Bins used to measure particle size versus distance from the crack. (e) Mean particle size (area) data for $\mathrm{SbSn}$ and $\mathrm{Ag}_{3} \mathrm{Sn}$.

the accelerated coarsening of SbSn near the component-side and (iii) the SbSn particles in regions containing recovered subgrains, recrystallised grains, and/or cracks, a higher-resolution EBSD map was collected from a fractured 192CABGA joint. The results are presented in Figs. 11, 12 and 13.

Analysis of the EBSD dataset in Fig. 11b revealed $86 \mathrm{Cu}_{6} \mathrm{Sn}_{5}$ intermetallic crystals (excluding the interfacial $\mathrm{Cu}_{6} \mathrm{Sn}_{5}$ IMC layer), about $18 \%$ of which were found to have at least one SbSn particle attached, that had the OR described in Fig. 10. This was a very low fraction $(\sim 2 \%)$ of the overall number of SbSn particles counted in the EBSD map-839. The majority of SbSn particles $(\sim 98 \%)$ formed inside $\beta$-Sn dendrites. In case SbSn was found at the interface with the $\mathrm{Cu}_{6} \mathrm{Sn}_{5}$ crystals, typically it was significantly larger and had a non-faceted shape (i.e. demonstrated in Fig. 10). Frequently, such SbSn particles measuring a few microns in size were also detected to have the OR (summarized in Eq. 2) with $\mathrm{Cu}_{6} \mathrm{Sn}_{5}$ grains from the interfacial IMC layer. However, no noticeable accumulation of SbSn phase was found on the interfacial IMC layer.

During solid-state precipitation, the $\beta-\mathrm{Sn} / \mathrm{SbSn}$ OR was preserved across (i) the undeformed areas of $\beta$-Sn in the bulk (e.g. Fig. 9 and particle 1 in Fig. 11a), (ii) in $\beta$-Sn subgrains where multiple SbSn particles rotated together with the matrix (e.g. particle 2 in Fig. 11b) and (iii) even in the recrystallized $\beta$-Sn region where some of the highly coarsened SbSn particles were found to share the same OR with one of the neighbouring $\beta$-Sn grains (e.g. particle 3 in Fig. 11b). This underlines the strong preference for the orientation relationship and the importance of low-energy interfaces in the precipitation and coarsening of SbSn in $\beta$-Sn.

As can be inferred from Fig. 11, larger SbSn particles tended to accumulate and develop on the recrystallised $\beta$-Sn grain boundaries in the stress- 

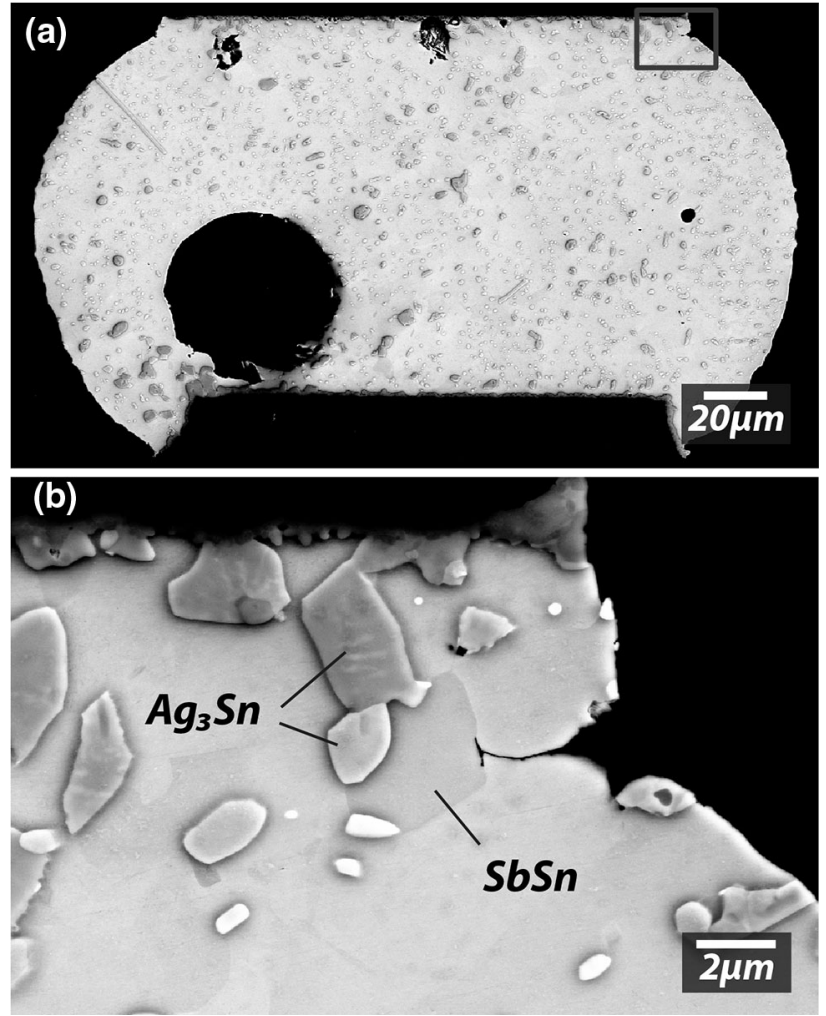

Fig. 13. (a-b) Example of a crack being deflected by a large SbSn particle in the recrystallised $\beta$-Sn region near the component side (84CTBGA joint).

localized area, whereas the recrystallised $\beta$-Sn grains themselves contained very low amounts of SbSn cuboids. Quantification of EBSD data in Fig. 11c showed that $\sim 90 \%$ (234 out of 260 ) of SbSn particles in the recrystallized region are located at the recrystallised $\beta$-Sn grain boundaries. Such localisation of SbSn particles at recrystallised grain boundaries seem to be able to impede crack propagation, as illustrated in Fig. 13, where a developing corner crack was deflected by a large $\mathrm{SbSn}$, although it is anticipated that the loss of submicron SbSn cuboids within the recrystallised $\beta$ Sn grains will lead to a significant loss of local creep strength in this region.

Figure 12 quantifies the size distribution of SbSn and $\mathrm{Ag}_{3} \mathrm{Sn}$ particles as a function of the distance to the crack. It can be seen that, on average, the size of both types of intermetallic particles is $4-5$ times larger in the areas around the crack ( $\beta$-Sn recrystallized zone) than in the low-deformation region far from the crack. The reasons for the rapid coarsening of the IMC particles in the stress-localized regions include enhanced strain-induced coarsening, which precedes $\beta$-Sn recrystallization ${ }^{58}$ and, probably, also more rapid grain-boundary diffusion once $\beta$-Sn recrystallization has occurred. As can be also seen from Fig. 12, in the undeformed area further in the bulk, the size of SbSn precipitates was generally smaller compared to the that of $\mathrm{Ag}_{3} \mathrm{Sn}$ particles, measuring on average $0.6 \mu \mathrm{m}^{2}$ versus $\sim 1.1 \mu \mathrm{m}^{2}$ for $\mathrm{Ag}_{3} \mathrm{Sn}$. Please note that the EBSD detection limit for the settings used in Fig. 12 was $0.46 \mu \mathrm{m}^{2}$ which omitted finer SbSn precipitates during the quantification of the particle size distribution.

\section{CONCLUSIONS}

Microstructure and damage evolution have been studied in $\mathrm{Sn}-3.8 \mathrm{Ag}-0.9 \mathrm{Cu}-5.5 \mathrm{Sb}-0.5 \mathrm{In}$ BGA solder joints that were part of an industrial consortium project on accelerated thermal cycling (ATC) performance of emerging third-generation $\mathrm{Pb}$-free solders in harsh conditions. ${ }^{16}$ This composition was selected as a near-eutectic $\mathrm{Sn}-\mathrm{Ag}-\mathrm{Cu}$ solder containing a relatively high $\mathrm{Sb}$ content as the major addition, and because it significantly outperformed SAC305 in both packages and all three ATC profiles $\left(0 / 100^{\circ} \mathrm{C},-40 / 125^{\circ} \mathrm{C},-55 / 125^{\circ} \mathrm{C}\right)$. The following conclusions can be drawn:

- For Sn-3.8Ag-0.9Cu-5.5Sb-0.5In, the great majority of joints contained a $\beta$-Sn single grain (i.e. one crystallographic orientation).

- The SbSn phase precipitated preferentially on $\mathrm{Cu}_{6} \mathrm{Sn}_{5}$ and inside $\beta$-Sn dendrites where the $\mathrm{Sb}$ solute content was highest at the end of solidification, providing strengthening particles in the dendritic $\beta$-Sn to supplement strengthening from the $\mathrm{Ag}_{3} \mathrm{Sn}$ particles in the eutectic regions.

- During precipitation of $\mathrm{SbSn}$ on $\mathrm{Cu}_{6} \mathrm{Sn}_{5}$, the following highly reproducible orientation relationship was measured: $(11 \overline{2} 0)_{\mathrm{Cu} 6 \mathrm{Sn} 5} \|(110)_{\mathrm{SbSn}}$ and $[0001]_{\mathrm{Cu} 6 \mathrm{Sn} 5} \|[111]_{\mathrm{SbSn}}$.

- During precipitation of SbSn in $\beta$-Sn, another highly reproducible OR was detected: $(100)_{\beta \mathrm{Sn}} \|$ $(100)_{\mathrm{SbSn}}$ and $[001]_{\beta \mathrm{Sn}} \|[001]_{\mathrm{SbSn}}$.

- SbSn particle coarsening followed a similar trend as $\mathrm{Ag}_{3} \mathrm{Sn}$, with enhanced particle coarsening in the region of localised shear strain and recrystallisation near the component side.

- In the region of localised recrystallisation, $\mathrm{SbSn}$ particles were preferentially located at recrystallised grain boundaries where they may provide pinning and reduce grain boundary sliding and rotation. Some of these SbSn particles were also found to deflect cracks. However, in this localised region, the SbSn particles were the most heavily coarsened and are likely to be less effective strengtheners than SbSn in the less deformed regions that were numerous sub-micrometre cuboids. 


\section{ACKNOWLEDGMENTS}

This work was partially funded by UK EPSRC Grant EP/R018863/1. The authors gratefully acknowledge the use of characterisation facilities within the Harvey Flower Electron Microscopy Suite, Department of Materials, Imperial College London.

\section{CONFLICT OF INTEREST}

The authors declare that they have no conflict of interest.

\section{OPEN ACCESS}

This article is licensed under a Creative Commons Attribution 4.0 International License, which permits use, sharing, adaptation, distribution and reproduction in any medium or format, as long as you give appropriate credit to the original author(s) and the source, provide a link to the Creative Commons licence, and indicate if changes were made. The images or other third party material in this article are included in the article's Creative Commons licence, unless indicated otherwise in a credit line to the material. If material is not included in the article's Creative Commons licence and your intended use is not permitted by statutory regulation or exceeds the permitted use, you will need to obtain permission directly from the copyright holder. To view a copy of this licence, visit http://creativecommons.org/licenses/by/4.0/.

\section{REFERENCES}

1. R.J. Coyle, K. Sweatman, and B. Arfaei, JOM 67, 2394 (2015).

2. R.J. Coyle, R. Parker, K. Howell, D. Hillman, J. Smetana, G. Thomas, S. Longgood, M. Osterman, E. Lundeen, P. Snugovsky, J. Silk, A. Kleyner, K. Sweatman, R. Padilla, T. Yoshikawa, J. Bath, M. Holtzer, H. Zhang, J. Noiray, F. Duondel, R. Aspandiar, and J. Wilcox, in SMTA International (Rosemont, IL, USA, 2016), pp. 188-196.

3. M. Celikin, M. Maalekian, and M. Pekguleryuz, J. Electron. Mater. 48, 5562 (2019).

4. S. Hamasha, F. Akkara, M. Abueed, M. Rababah, C. Zhao, S. $\mathrm{Su}$, J. Suhling and J. Evans, in 2018 IEEE 68th Electronic Components and Technology Conference (ECTC) (2018), pp. 2032-2040.

5. C.J. Thwaites, Int. Mater. Rev. 29, 45 (1984).

6. J. Glazer, Int. Mater. Rev. 40, 65 (1995).

7. M. Dias, T. Costa, T. Soares, B. Silva, N. Cheung, J. Spinelli, and A. Garcia, J. Electron. Mater. 47, 1647 (2018).

8. Z. Liu, H. Pan, Y. Wang, L. Xu, J. Lu, D. Wu, J. Wu, M. Li and L. Gao, in 2018 19th International Conference on Electronic Packaging Technology (ICEPT) (2018), pp. 14001405.

9. A. El-Daly, Y. Swilem, and A.E. Hammad, J. Alloys Compd. 471, 98 (2009).

10. H. Schoeller, S. Bansal, A. Knobloch, D. Shaddock and J. Cho, in ASME 2008 International Mechanical Engineering Congress and Exposition (2008), pp. 25-32.

11. H. Schoeller, S. Bansal, A. Knobloch, D. Shaddock, and J. Cho, J. Electron. Mater. 38, 802 (2009).

12. R. Mahmudi, A.R. Geranmayeh, M. Bakherad, and M. Allami, Mater. Sci. Eng. 457, 173 (2007).

13. H. Vafaeenezhad, S.H. Seyedein, M.R. Aboutalebi, A.R. Eivani, and O. Nikan, Microelectron. Eng. 207, 55 (2019).
14. T. Kobayashi, K. Kobayashi, K. Mitsui, and I. Shohji, Adv. Mater. Sci. Eng. 2018, 1416942 (2018).

15. N. Hiyoshi, Acta Metall. Sin. Engl. 30, 851 (2017).

16. R. Coyle, C. Johnson, D. Hillman, R. Parker, M. Osterman, J. Smetana, T. Pearson, B. Arfaei, K. Howell, S. Longgood, A. Kleyner, J. Silk, A. Delhaise, H. Zhang, J. Geng, R. Pandher and E. Lundeen, in SMTA International (Rosemont, IL, USA, 2019).

17. S.A. Belyakov, B. Arfaei, C. Johnson, K. Howell, R. Coyle and C.M. Gourlay, in SMTA International (Rosemont, IL, USA, 2019).

18. R. Coyle, D. Hillman, R. Parker, C. Johnson, M. Osterman, B. Arfaei, J. Smetana, A. Delhaise, K. Howell, S. Longgood, A. Kleyner, J. Bath, H. Zhang and J. Geng, in SMTA International (Rosemont, IL, USA, 2018).

19. IPC-9701A: Performance Test Methods and Qualification Requirements for Surface Mount Solder Attachments (IPC Bannockburn, IL, 2006).

20. C.A. Schneider, W.S. Rasband, and K.W. Eliceiri, Nat Method 9, 671 (2012).

21. W.M. Jones and E.G. Bowen, Nature 126, 846 (1930).

22. G. Hägg and A.G. Hybinette, Lond. Edinb. Dublin Philos. Mag. J. Sci. 20, 913 (1935).

23. L. Norén, R.L. Withers, S. Schmid, F.J. Brink, and V. Ting, J. Solid State Chem. 179, 404 (2006).

24. S. Lidin, J. Christensen, K. Jansson, D. Fredrickson, R. Withers, L. Norén, and S. Schmid, Inorg. Chem. 48, 5497 (2009).

25. C. Schmetterer, J. Polt, and H. Flandorfer, J. Alloys Compd. 743, 523 (2018)

26. C. Schmetterer, J. Polt, and H. Flandorfer, J. Alloys Compd. 728, 497 (2017).

27. A.K. Larsson, L. Stenberg, and S. Lidin, Acta Crystallogr. B 50, 636 (1994).

28. K. Nogita, C.M. Gourlay, S.D. McDonald, Y.Q. Wu, J. Read, and Q.F. Gu, Scr. Mater. 65, 922 (2011).

29. B. Peplinski, G. Schulz, D. Schultze, and E. Schierhorn, Mater. Sci. Forum 228, 577 (1996).

30. A. Leineweber, C. Wieser, and W. Hügel, Scr. Mater. 183, 66 (2020).

31. M. Wolcyrz, R. Kubiak, and S. Maciejewski, Phys. Status Solidi B Basic Res. 107, 245 (1981).

32. A. Gangulee, G.C. Das, and M.B. Bever, Metall. Trans. 4 , 2063 (1973).

33. W. Fairhurst and J.B. Cohen, Acta Crystall. B 28, 371 (1972).

34. B. Arfaei, N. Kim, and E.J. Cotts, J. Electron. Mater. 41, 362 (2012).

35. R. Darveaux, C. Reichman, C.J. Berry, H. Wen-Sung, A Syed, K.C. Woo, R.J. Hun and K.T. Seong, in 2008 58th Electronic Components and Technology Conference (2008), pp. 113-122.

36. W. Engelmaier, Solder. Surf. Mt. Technol. 1, 14 (1989).

37. S. Yoon, Z. Chen, M. Osterman, B. Han and A. Dasgupta, in Proceedings Electronic Components and Technology, 2005. ECTC '05 (2005), pp. 1210-1214.

38. L. Yin, L. Wentlent, L. Yang, B. Arfaei, A. Oasaimeh, and P. Borgesen, J. Electron. Mater. 41, 241 (2012).

39. S. Dunford, S. Canumalla and P. Viswanadharn, in 2004 Proceedings. 54th Electronic Components and Technology Conference (IEEE) (2004), pp. 726-736, Vol. 1.

40. B. Arfaei, S. Mahin-Shirazi, S. Joshi, M. Anselm, P. Borgesen, E. Cotts, J. Wilcox and R. Coyle, in 2013 IEEE 63rd Electronic Components and Technology Conference (2013), pp. 976-985.

41. T.T. Mattila and J.K. Kivilahti, IEEE Trans. Compon. Packag. Technol. 33, 629 (2010).

42. K.N. Subramanian, T.R. Bieler, and J.P. Lucas, J. Electron. Mater. 28, 1176 (1999).

43. M. Kerr and N. Chawla, Acta Mater. 52, 4527 (2004).

44. I. Dutta, C. Park, and S. Choi, Mater. Sci. Eng. A 379, 401 (2004).

45. H.E. Swanson and E. Tatge, Standard X-ray diffraction powder patterns (Washington: National Bureau of Standards, 1953), pp. 1-95. 
46. D.W. Henderson, T. Gosselin, A. Sarkhel, S.K. Kang, W.K. Choi, D.Y. Shih, C. Goldsmith, and K.J. Puttlitz, J. Mater. Res. 17, 2775 (2002).

47. D.R. Frear, J.W. Jang, J.K. Lin, and C. Zhang, JOM 53, 28 (2001).

48. S. Kim, S.H. Huh, and K. Suganuma, Mater. Sci. Eng. A Struct. 333, 106 (2002).

49. J. Zhao, Y. Miyashita, and Y. Mutoh, Int. J. Fatigue 23, 723 (2001).

50. R.J. McCabe and M.E. Fine, Metall. Mater. Trans. A 33, 1531 (2002).

51. S.A. Belyakov, J. Xian, G. Zeng, K. Sweatman, T. Nishimura, T. Akaiwa, and C.M. Gourlay, J. Mater. Sci. Mater. Electron. 30, 378 (2019).

52. B.F. Dyson, T.R. Anthony, and D. Turnbull, J. Appl. Phys. 38,3408 (1967).
53. D.C. Yeh and H.B. Huntington, Phys. Rev. Lett. 53, 1469 (1984).

54. B.F. Dyson, J. Appl. Phys. 37, 2375 (1966).

55. J.W. Xian, S.A. Belyakov, M. Ollivier, K. Nogita, H. Yasuda, and C.M. Gourlay, Acta Mater. 126, 540 (2017).

56. L. Ratke and P.W. Voorhees, Growth and Coarsening: Ostwald Ripening in Materials Processing (Berlin: Springer, 2002).

57. J. Ardell, Acta Metall. 20, 61 (1972).

58. R. Parker, R. Coyle, G. Henshall, J. Smetana, and E. Benedetto, in SMTAI 2012 (Orlando, FL, 2012), pp. 348-358.

Publisher's Note Springer Nature remains neutral with regard to jurisdictional claims in published maps and institutional affiliations. 